\title{
Los Estados surgidos de la antigua Unión Soviética y su articulación territorial en torno a Rusia
}

\author{
José SÁNCHEZ SÁnCHEZ *
}

\section{INTRODUCCIÓN}

La Unión de Repúblicas Socialistas Soviéticas (URSS) era, ante todo, un hecho político y se extendía por un inmenso territorio de 22 mill. de $\mathrm{km}^{2}$. Nacida de la revolución de 1917, la URSS heredó un imperio multinacional, con más de 100 pueblos, formado tras varios siglos de expansión y conquistas rusas. Fue una primera potencia demográfica, económica y militar. Sin embargo, cuando nadie lo esperaba, se desintegró sin resistencia alguna y con una rapidez que a todos sorprendió.

Hoy el gran gigante euroasiático ha dado paso a un conjunto de 15 Estados independientes que no terminan de encontrar las condiciones adecuadas para el desarrollo económico y la convivencia pacífica. Un nuevo sistema de relaciones está surgiendo entre los antiguos componentes de la URSS: la Comunidad de Estados Independientes (CEI), de la que forman parte todas las ex-repúblicas soviéticas, excepto los tres países bálticos (mapa de la Fig. 1, y cuadro oㅜ 1).

Inmersos en un complicado proceso de transición, estos nuevos Estados se enfrentan hoy a numerosos problemas económicos, sociales y geopolíticos, mientras intentan construir una nueva articulación territorial en torno a la poderosa Rusia.

\section{LOS NUEVOS ESTADOS, ECONOMIAS DE TRANSICIÓN}

Como los países ex-socialistas de la Europa del Este, todos los Estados surgidos de la antigua Unión Soviética se hallan hoy caracterizados por

* UNED, Madrid. 


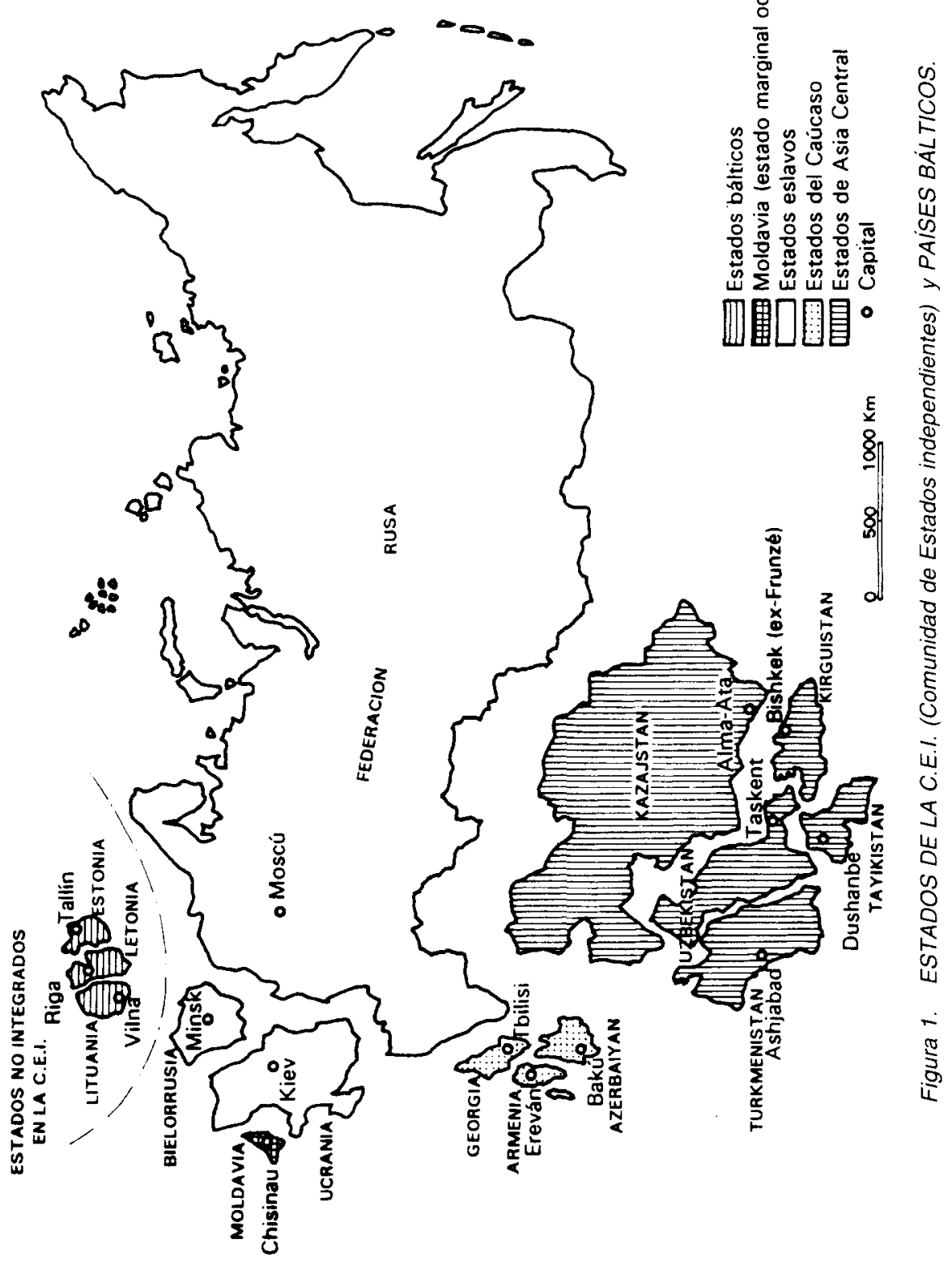


CUADRO 1. REPÚBLICAS DE LA EX-UNIÓN SOVIÉTICA-ESTADOS DE LA CEI

\begin{tabular}{|c|c|c|c|c|}
\hline & $\begin{array}{c}\text { EXTENSION } \\
\mathrm{KM}^{2}\end{array}$ & $\begin{array}{l}\text { POBLACIÓN } \\
\text { MILES HABS. (1993) }\end{array}$ & $\begin{array}{c}\text { PNB } \\
\text { MILL. DÓL. }\end{array}$ & $\begin{array}{c}\text { RENTA/HAB. } \\
\text { DÓLARES (1993) }\end{array}$ \\
\hline \multicolumn{5}{|c|}{ Repúblicas Bálticas (no integradas en la CEI) } \\
\hline Estonia ............................ & 45.215 & 1.500 & 4.000 & 2.500 \\
\hline Letonia............................ & 64.500 & 2.630 & 4.600 & 1.800 \\
\hline Lituania........................... & 65.200 & 3.760 & 6.300 & 1.700 \\
\hline \multicolumn{5}{|l|}{ Repúblicas eslavas } \\
\hline Rusia ............................... & 7.045 .400 & $\uparrow 48.600$ & 330.000 & 2.200 \\
\hline Bielorrusia ...................... & 207.600 & 10.400 & 23.200 & 2.220 \\
\hline Ucrania ........................... & 603.700 & 52.300 & 82.000 & 1.560 \\
\hline \multicolumn{5}{|l|}{ República en el extremo Occiental } \\
\hline Moldavia ........................... & 33.700 & 4.370 & 7.000 & 1.600 \\
\hline \multicolumn{5}{|l|}{ Repúblicas del Cáucaso } \\
\hline Georgia.......................... & 69.700 & 5.500 & 4.000 & 730 \\
\hline Armenia .......................... & 29.800 & 3.310 & 2.800 & 910 \\
\hline Azerbaiyán ........................... & 86.600 & 7.300 & 6.000 & 800 \\
\hline \multicolumn{5}{|l|}{ Repúblicas de Asia Central } \\
\hline 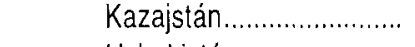 & 2.717 .300 & 17.210 & 33.600 & 1.950 \\
\hline Uzbekistán........................ & 447.400 & 20.955 & 20.000 & 900 \\
\hline Turkmenistán.................... & 488.100 & 3.900 & 6.000 & 1.600 \\
\hline Kirguistán ........................ & 198.500 & 4.550 & 3.000 & 700 \\
\hline Tayikistán .......................... & 143.100 & 5.650 & 3.200 & 600 \\
\hline
\end{tabular}

Fuente: Atlaseco, 1995

una "economía de transición» (Kolossov, VL., 1993). Sus estructuras socioeconómicas y territoriales combinan algunas caracteristicas de los paises desarrollados, del centro, con otras más propias de las regiones periféricas o subdesarrolladas.

Por un lado, el proceso de industrialización se halla muy avanzado, o incluso terminado (más del $30 \%$ de población activa industrial), y el sector terciario, menos desarrollado; en algunos Estados, como Letonia, Rusia y Ucrania, empieza ya a superar el $50 \%$ de la población activa (cuadro $\mathrm{n}^{\circ}$ 2). Por el contrario, muchas ramas de la economía utilizan todavía tecnología desfasada y, lo más grave, la producción de bienes de consumo es totalmente insuficiente para cubrir las necesidades de la población. El crecimiento se realiza a base de despilfarrar los grandes recursos naturales, mediante procedimientos que generan un grave deterioro del medio ambiente. 


\section{CUADRO 2. REPÚBLICAS DE LA EX-UNIÓN SOVIÉTICA-ESTADOS} DE LA CEI

\begin{tabular}{|c|c|c|c|c|}
\hline & \multicolumn{4}{|c|}{ POBLACIÓN ACTIVA POR SECTORES (\%) } \\
\hline & AGRICULTURA & MINERIA & INDUSTRIA & SERVICIOS \\
\hline \multicolumn{5}{|c|}{ Repúblicas Bálticas (no integradas en la CEI) } \\
\hline 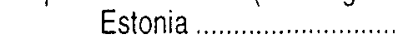 & 18 & 3 & 39 & 30 \\
\hline Letonia............................ & 16 & 0 & 30 & 54 \\
\hline Lituania............................ & 30 & 0 & 40 & 30 \\
\hline \multicolumn{5}{|l|}{ Repúblicas eslavas } \\
\hline Rusia ............................... & 13 & 7 & 30 & 50 \\
\hline Bielorrusia ........................ & 19 & 1 & 30 & 50 \\
\hline 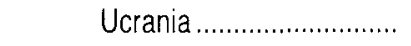 & 19 & 3 & 37 & 41 \\
\hline \multicolumn{5}{|l|}{ Republica en el extremo Occidental } \\
\hline Moldavia ............................ & 35 & 0 & 28 & 37 \\
\hline \multicolumn{5}{|l|}{ Repúblicas del Cáucaso } \\
\hline 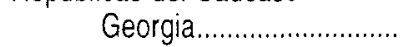 & 27 & 0 & 28 & 45 \\
\hline Armenia ......................... & 12 & 3 & 52 & 33 \\
\hline Azerbaiyán ........................ & 34 & 4 & 20 & 42 \\
\hline \multicolumn{5}{|l|}{ Repúblicas de Asia Central } \\
\hline Kazajstán........................... & 26 & 8 & 27 & 39 \\
\hline Uzbekistán........................ & 34 & 8 & 18 & 40 \\
\hline Turkmenistán.................... & 42 & 5 & 25 & 28 \\
\hline Kirguistán .......................... & 36 & 2 & 25 & 37 \\
\hline Tayikistán ......................... & 42 & 0 & 38 & 20 \\
\hline
\end{tabular}

Fuente: Atlaseco, 1995

La crisis económica, que afecta a todas las repúblicas ex-soviéticas desde 1990 (Crosnier, M.-A., 1993; Palazuelos, E., 1995 y Sánchez, J., 1996), ha colocado a las poblaciones de los nuevos Estados en una situación de indigencia generalizada. Los niveles de renta per cápita se hallan muy próximos al de los países menos desarrollados (cuadro $\mathrm{n}^{\circ} \mathbf{1}$ y mapa de la Fig. 2) El nivel mas alto en 1993 fue de 2.500 dólares por habitante en Estonia, cuando España superaba los 12.000. Frente a los 24.235 dólares por habitante de Estados Unidos, Rusia sólo registraba 2.200, Kazajstán, 1989 y Ucrania, 1500. En los Estados Caucásicos, debido a las guerras desastrosas, ni siquiera se llegaba a los 1.000 dólares por habitante, lo mismo que en la mayor parte de los paises de Asia Central. Hay quien opina que las consecuencias de este período de transición y crisis esta llevando a estos Estados a situaciones propias del Tercer Mundo (Nagels, J., 1993).

La transición a la economía de mercado es un proceso complejo y lleno de dificultades. El ritmo de las reformas está resultando más lento de lo previsto y muy desigual de unas repúblicas a otras, lo que retrasa enormemente la 


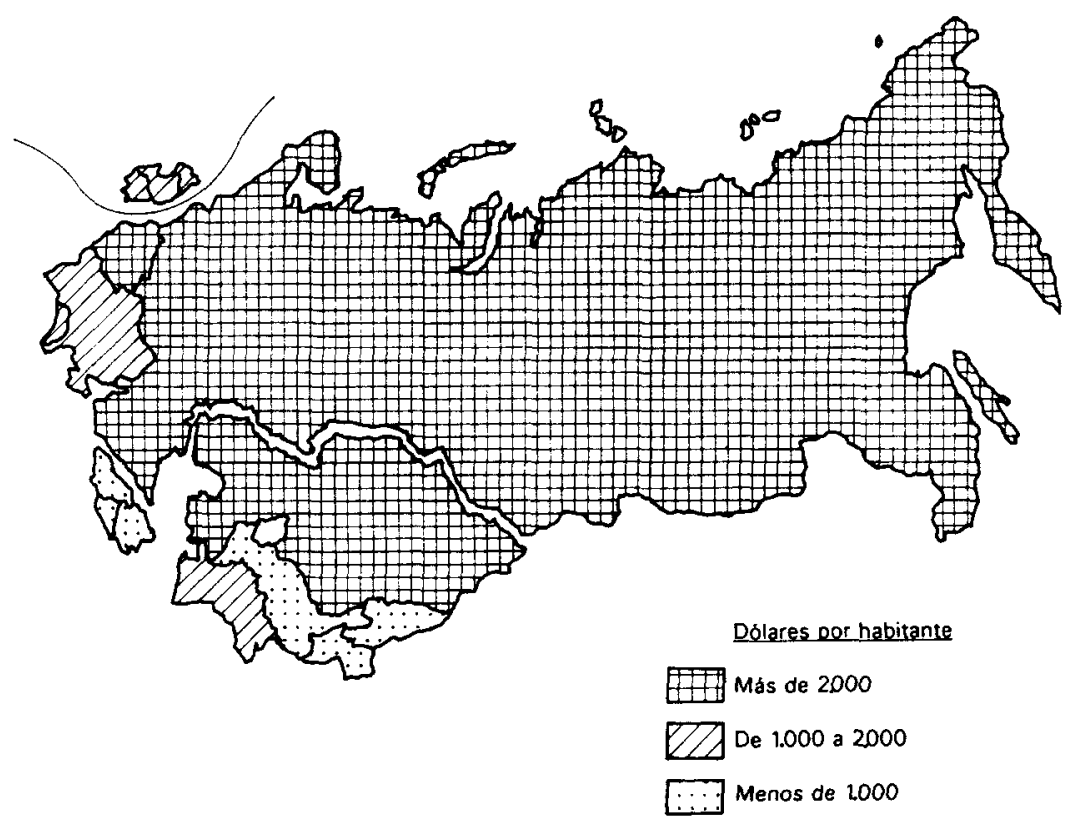

Figura 2. Estados surgidos de la URSS. Renta per capita (1993).

puesta en funcionamiento de un mercado común bien organizado. Todavía en 1994 la mayor parte de las producciones en todos los Estados se haIlan monopolizadas o controladas por grandes empresas estatales (Kerblay, B., 1994 ).

Desde el punto de vista de las estructuras territoriales, se hace patente la contraposición entre regiones urbanas y rurales, entre las capitales y las provincias, entre regiones y Estados europeos y asiáticos. Unos se hallan dotados de mejores infraestructuras, servicios de mayor calidad y mejor accesibilidad; otros están más desatendidos, con infraestructuras insuficientes, bajo nivel de accesibilidad y servicios de peor calidad.

Tras la inicial euforia independentista, el realismo de la vida cotidiana está obligando a los dirigentes políticos de los nuevos Estados a plantearse de nuevo las relaciones con las demás repúblicas ex-soviéticas, especialmente con Rusia. Ésta muestra claramente sus grandes ambiciones geopolíticas, derivadas de su gran potencial económico y de su posición geográfica central, rodeada de una orla de pequeños Estados, que generan focos de inestabilidad y hacen vulnerables sus fronteras. A Rusia le interesa restablecer las relaciones con las repúblicas ex-soviéticas, que pueden contribuir a realzar su papel de líder en el contexto internacional. 
Por ello, trata por todos los medios de consolidar la Comunidad de Estados Independientes, dotándola de órganos ejecutivos, como el Consejo de Jefes de Estado y el Consejo de Jefes de Gobierno, creados en la Carta institucional de la CEI (1993). A la vez, establece acuerdos de cooperación con otros Estados, tanto en el ámbito militar (Tratado de Seguridad Colectiva), como en el campo económico, comercial, cultural y científico.

Alrededor de Rusia se está formando, así, un nuevo conjunto geoeconómico que trata de abrirse al mundo, pero que se halla aún muy cerrado sobre sí mismo. Esta dinámica contradictoria se explica por la fuerte posición que sigue manteniendo el Estado y la peligrosa presencia de conflictos geopolíticos, todavía no resueltos. La diferente estructura territorial y económica, junto a la complejidad étnica y al desigual avance de las reformas hacen de este inmenso territorio un espacio lleno de contrastes y tensiones (cuadros $n^{\circ} 1$ y 2 ).

En el centro, destaca Rusia, con sus enormes recursos naturales y sus aspiraciones a mantener el papel de gran potencia mundial, heredera de la URSS. Inmersa en una grave crisis, corre el peligro de perder su potencial económico, si no soluciona pronto sus problemas internos. Junto a ella, las otras dos repúblicas eslavas presentan economías y poblaciones muy entrelazadas con Rusia, aunque mantienen posturas diferentes respecto a la CEI: Bielorrusia, con firme voluntad integradora; Ucrania, con deseos de preservar su independencia. En el frente occidental, los tres Estados Bálticos han sido los únicos que han podido quedar al margen de este fuerte movimiento de recomposición; al contrario de lo que ha ocurrido a Moldavia.

En el Sur, se sitúan los Estados más pobres y más conflictivos, desde el punto de vista étnico y religioso: los caucásicos (Georgia, Armenia y Azerbaiyán) y los de Asia Central (Kirguistán, Uzbekistán, Turkmenistán y Tayikistán). Kazajstán, asiático, pero en parte poblado por europeos, extenso, rico y multiétnico, constituye un firme aliado de Rusia; ésta intenta tutelar todo el flanco meridional de la antigua URSS, para dar estabilidad a sus fronteras y afirmar su papel hegemónico.

\section{RUSIA, LA GRAN POTENCIA}

\section{a) Los grandes recursos}

Con 17 mill. de $\mathrm{km}^{2}$ y 150 mill. de habitantes la importancia de Rusia en el concierto mundial es indiscutible. Lo mismo que su protagonismo en el 
interior del espacio ex-soviético: proporciona el 61\% del P.I.B. del conjunto de la antigua Unión Soviética, el 50\% de la producción agrícola, el 55\% del carbón, el $64 \%$ de la producción industrial, el $91 \%$ del petróleo y el $70 \%$ de las exportaciones. En su territorio se sitúan cinco de las seis grandes regiones industriales de la ex-URSS, cuenta con dos metrópolis mundiales (Moscú y San Petersburgo) y dispone de un gran poderio militar, reforzado con la posesión de armas nucleares.

Como gran potencia es la heredera de la Unión Soviética en los organismos internacionales, reconocida por todas las demás repúblicas ex-soviéticas. Sin embargo, desde la caída de la URSS su potencial productivo ha perdido importancia respecto a Estados Unidos.

Cuadro 3. COMPARACIÓN DE ALGUNAS PRODUCCIONES DE LA URSS, EEUU y RUSIA

\begin{tabular}{lrrrrrr}
\hline & \multicolumn{2}{c}{1946} & \multicolumn{2}{c}{1987} & \multicolumn{2}{c}{1993} \\
\hline PRODUCCIÓN & URSS & EEUU & URSS & EEUU & RUSIA & EEUU \\
\hline Hulla (mill. t) & 164 & 537 & 589 & 758 & 305 & 825 \\
Petróleo (mill. t) & 22 & 234 & 624 & 460 & 352 & 343 \\
Gas natural (miles & & & & & & \\
de mill. de m ${ }^{3}$ ) & 4 & 117 & 727 & 462 & 618 & 522 \\
Electricidad (miles & & & & & & \\
de mill. de Kwh) & 18 & 269 & 1.665 & 2.774 & 1.237 & 3.292 \\
Acero (mill. de tn) & 13 & 60 & 162 & 82 & 132 & 79 \\
Algodón (mill. de tn) & 0,5 & 1,9 & 2,5 & 3,2 & - & 3,7 \\
\hline
\end{tabular}

Fuente: Images Économiques du Monde y Atlaseco

Pero la fuerza económica de Rusia se ve notablemente incrementada a través de su asociación a los otros dos Estados eslavos, Bielorrusia y Ucrania, que forman el núcleo central de la CEI. Con 18 mill. de $\mathrm{km}^{2}$ y 211 mill. de habs., generan el $80 \%$ del P.I.B., el $87 \%$ de la capacidad industrial y el $75 \%$ de la agrícola de todo el espacio exsoviético.

La fuerza que tiene este núcleo se basa en la homogeneidad de la familia eslava que constituye la mayoría absoluta en las tres repúblicas ( $96 \%$ en Ucrania, $95 \%$ en Bielorrusia y $85 \%$ en Rusia), en la larga historia que han construido juntas (llevan unidas desde los siglos XVI-XVII) y en la fuerte integración de sus economías, cuyo funcionamiento independiente hoy parece impensable. 


\section{b) Estructura territorial}

Lo mismo que ocurría con la URSS, en el territorio de Rusia se distingue una parte europea y otra asiática (mapas de las Fig. 3, 4 y 5). En la Rusia europea, de viejo poblamiento y fuerte densidad humana, el dominio del espacio es completo, la red urbana, así como la de transportes y la infraestructura de comercio y de servicios está muy desarrollada.jDispone de gran cantidad de mano de obra, diversificada y especializada, de alto nivel de formación y en ella se sitúan los centros más importantes de cultura, de investigación y de decisión. Aquí se localizan igualmente las grandes regiones industriales y las mejores tierras agrícolas.

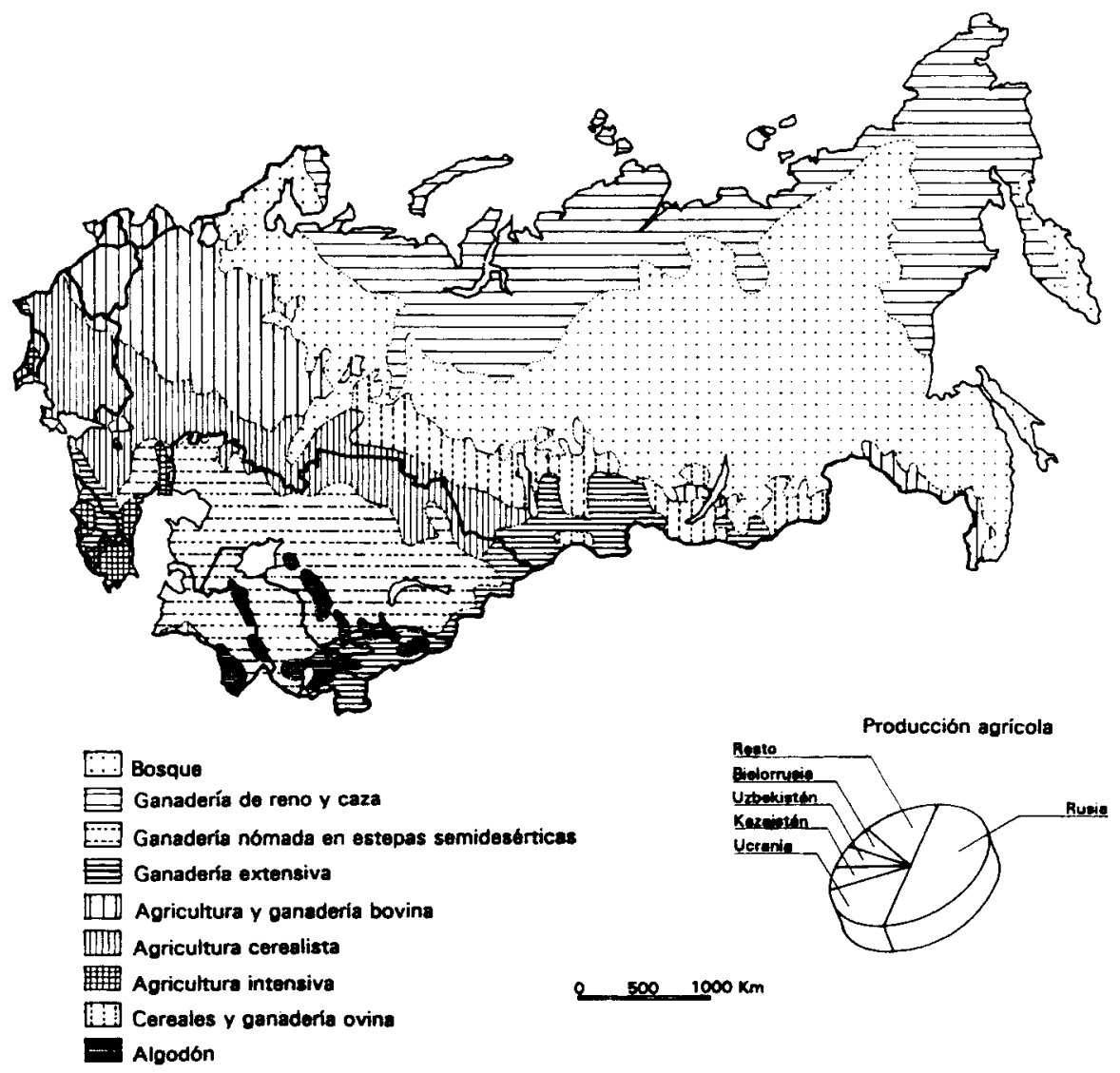

Figura 3. Aprovechamiento agricola, ganadero y forestal en los Estados de la CEI y Paises Bálticos. 


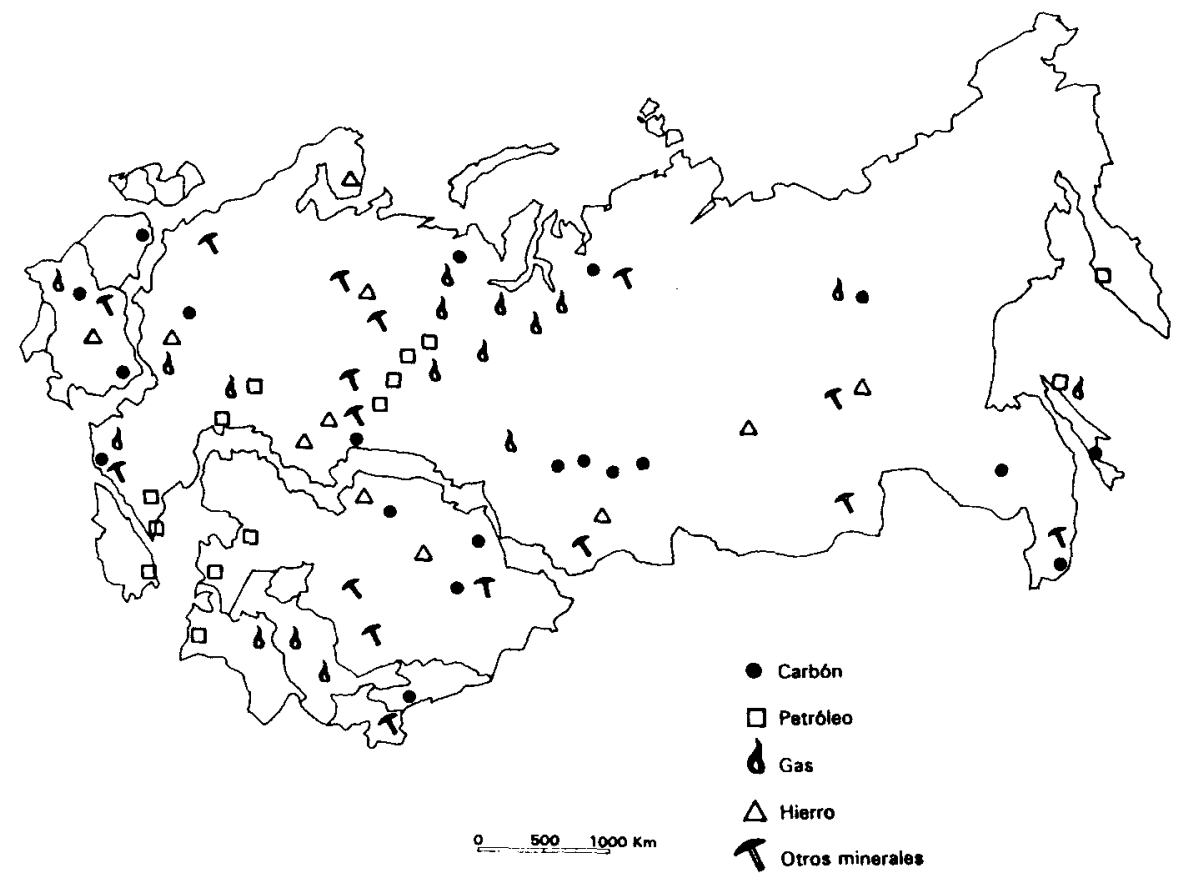

Figura 4. Principales yacimientos en los Estados de la CEI.

En primer lugar, destaca el gran centro económico ruso, constituido por las regiones industriales de Moscú y de San Petersburgo y las viejas regiones rurales. La primera es lo que se denomina uregión industrial central'», entre Smolensko, Rostroma, Nijni-Novgorod (ex-Gorki) y Briansk, con más de 30 ciudades mayores de 100.000 habs. ( 3 de ellas superan el millón) en un radio inferior a $400 \mathrm{~km}$ de Moscú ( 9 mill. de habs.). Detenta el monopolio de ciertas industrias ligeras (textil, cuero, imprenta, etc) y destaca como gran región de bienes de equipo: Nijni-Novgorov (ex-Gorki), con automóviles y motores; Ivanovo, con industria textil; Jaroslav, con productos químicos y farmacéuticos; Riazán, con maquinaria agrícola, etc.

La región de San Petersburgo (ex-Leningrado) se extiende en torno a esta ciudad por las proximidades del Báltico hasta el Norte de Bielorrusia. En la metrópoli de San Petersburgo (4,5 mill. de habs en 1989), gran puerto hacia el Atlántico, la industria se ha potenciado a partir de la explotación del Gran Norte y de la taiga. Además de las industrias navales, textil y de madera, más tradicionales, con el enorme potencial hidroeléctrico y con la apertura económica hacia el Oeste en las últimas décadas de la URSS se instalaron industrias de aluminio, 


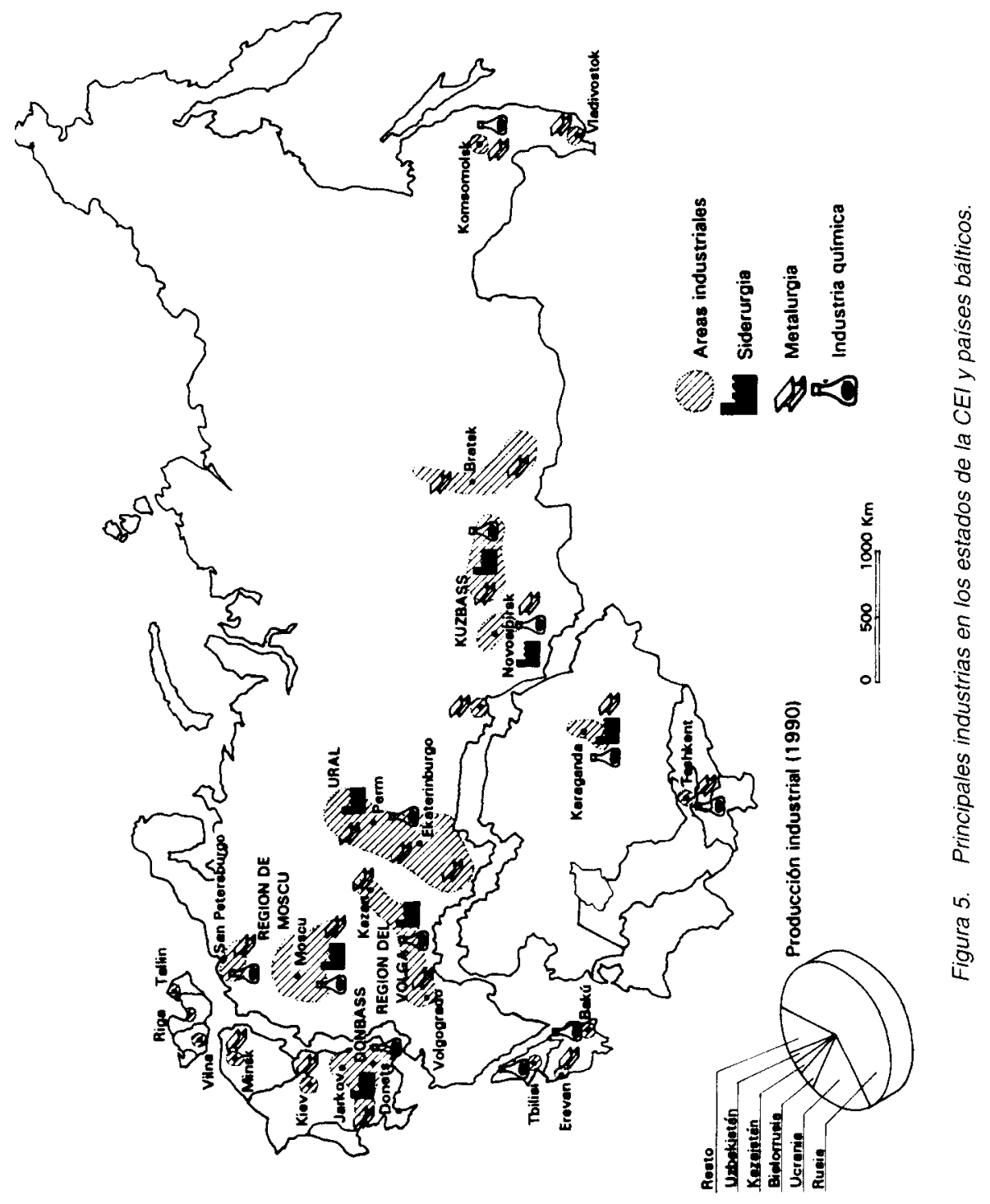


química, electromecánicas y electrónicas. La agricultura es excepcionalmente intensiva y el nivel de vida de la población llegó a ser relativamente elevado.

La viejas regiones rurales (Viejo Norte y Viejo Sur agrícolas) son regiones periféricas que se están transformando bajo la influencia de los centros urbanos. La emigración rural se dirige hacia las ciudades próximas que han crecido rápidamente. La franja rural del Norte evoluciona hacia su conversión en espacio de ocio; la del Sur, se está beneficiando de la industrialización que le llega por su proximidad a Ucrania.

Este gran centro económico se ve complementado con otras dos grandes regiones industriales, de formación más reciente: la región del Volga y la de los Urales. En la primera el gran rio constituye un eje dinámico, a lo largo del cual se suceden ciudades y núcleos industriales; cuatro aglomeraciones son millonarias: Kazán, Ruybichev, Saratov y Volgogrado. Es como el frente industrial de la Rusia europea. Su reserva energética es de primer orden. El Segundo Bakú fue el principal campo de petróleo hasta el descubrimiento de las reservas de Siberia. Esto se completa con la energía hidroeléctrica de las centrales del Volga. La industrialización recibió un gran impulso con el traslado de industrias siderúrgicas y mecánicas desde Ucrania durante la segunda guerra mundial. Despué, surgen las industrias agroalimentarias y las relacionadas con el petróleo (refinería y petroquímica) y, posteriormente, las consumidoras de electricidad. La diversificación se ha completado con la fabricación de tractores y maquinaria agricola y con la instalación del complejo automovilístico de Togliatti (cerca de Kuybichev).

La región de los Urales, cuya línea de cumbres ya no constituye frontera alguna, es una región de industrias pesadas en el corazón de Rusia y de la CEI. Durante años la mitad de las inversiones de la URSS se dirigió a esta región y entre 1926 y 1940 llegaron tres millones de personas. Hoy los Urales son la principal región minera de Rusia, con hierro, bauxita, minerales no ferrosos, oro, platino, etc. Predomina la industria básica y es la segunda región siderúrgica de Rusia, al mismo nivel que Ucrania, con la producción del 30\% del acero de la CEI. Recientemente se han potenciado también las industrias mecánicas y las químicas. La dependencia en productos agrícolas, materias primas y energía constituye su principal problema. Sobresalen las ciudades de Perm, Cheliabinsk, Ufa, Magnitogorsk y Ekaterimburgo (ex-Sverdlovsk) con 1,3 mill. de habs. en 1989, sede de numerosos establecimientos de enseñanza superior y centro de investigaciones atómicas. 
La Rusia asiática, extendida al Este de los Urales hasta el Pacífico (13 mill. de $\mathrm{km}^{2}$ ), ha sido $-y$ sigue siendo- el gran espacio pionero. Bajo condiciones naturales adversas, sólo existen islotes de explotación, sobre todo en la franja meridional que es la menos inhóspita y se halla recorrida por el Transiberiano. Pero esta Rusia asiática es una colosal reserva de minerales y fuentes de energía En ella se pueden distinguir cuatro grandes regiones: Siberia Occidehtal (piedemonte de los Urales), Siberia Central (cuencas del Obi-Irtys y del Yenisey), Siberia Oriental (más allá del Baikal) y Extremo Oriente (Región del Pacífico-Amur).

La abundancia de materias primas y de fuentes de energía son ya bien conocidas en la parte occidental, pero poco conocidas y mal evaluadas en el Gran Norte y Extremo Oriente. Es un territorio habitado mayoritariamente por rusos y los autóctonos sólo representan el $10 \%$ de toda la población; las densidades medias son ínfimas ( 5 habs $/ \mathrm{km}^{2}$ al Oeste, $1 \mathrm{hab} . / \mathrm{km}^{2}$ al Este)/Kuznetsk, con 30 habs. $/ \mathrm{km}^{2}$ es una isla en medio de un desierto humano. El poblamiento se ha hecho a base de ciudades-hongo, sin personalidad y siguiendo un modelo prefabricado, frío y monótono. Los islotes de actividad se alinean a lo largo del Transiberiano. La franja explotada se ha ensanchado al Sur con la línea férrea Yubsib y al norte con las de Sevsib y BAM. Los principales centros económicos consolidados son Kuznetsk y Novosibirsk; los nuevos polos, en fase de consolidación, están constituidos por las cuencas del Obi y del Angara-Baikal; y los nuevos polos en gestación se hallan situados a lo largo del BAM y en la cuenca del Amur.

En esta gran periferia explotada, según la terminologia de M.Cl. Maurel (1982), pueden individualizarse varios conjuntos regionales: la región de Kuznetsk y los frentes pioneros. La región de Kuznetsk se desarrolló con la creación del combinado Urales-Ruznetsk, que aprovechaba el carbón abundante y de fácil extracción (100 mill. de t.); después de su disolución, Kuznetsk ha mantenido un funcionamiento autónomo. La energía del Obi y sus afluentes todavía está poco aprovechada. El valor de la producción siderúrgica ha sido ya superado por el de la industria mecánica y sobre todo por el de la química, que elabora cada vez más materias plásticas y fibras sintéticas.Aunque en pequeña proporción, las industrias de consumo también están presentes en ciudades como Novokuznets, Kemerovo, Oms y sobre todo en Novosibirsk (1,4 mill. de habs. en 1989) que, con una importante función terciaria, constituye la base de partida para la conquista de Siberia.

Entre los espacios pioneros, unos son agrícolas, como las tierras vírgenes de la estepa, prolongadas en Kazajstán y dedicadas a la producción 
extensiva de cereales, y otros extractivos e industriales. Siberia Central y Extremo Oriente cada vez fue teniendo un mayor peso específico en el conjunto de la URSS y hoy lo tiene dentro de Rusia, por sus enormes recursos energéticos y mineros, aunque la colonización es difícil y muy costosa; su población es inferior a 30 mill. de habs. y hoy se siente la necesidad tanto de hombres como de capitales.

Con frecuencia la actividad se limita a la extracción de materias primas para su envio a las regiones europeas consumidoras, como el petróleo del Tercer Bakú, el gas natural del Gran Norte, los metales no ferroso de Norilsk, la electricidad térmica obtenida en los yacimientos de lignito de Kansk-Atchinsk, con una parte exportada a Kazajstán y Siberia meridional. Otras veces, los recursos son revalorizados mediante una primera elaboración al pie de la mina, como el aluminio y la pasta de papel, con el fin de aprovechar la electricidad del Yenisey-Angara, en la región de Baikal; y algunos centros industriales han conseguido un desarrollo notable, como Krasnoiarst, Irkutsk y, más recientemente, Bratsk y Chita, donde se han montado la metalurgia del aluminio, la industria química y de material eléctrico, de equipamiento minero y nuclear.

Las transformaciones se han realizado a base de inmigrantes europeos, quedando las poblaciones locales al margen de los cambios. Sin embargo, existe una gran dificultad en fijar a la población, lo que constituye el mayor obstáculo para el desarrollo de estos centros de actividad y de los nuevos que se quieren crear a lo largo de la línea ferroviaria BAM.

En Extremo Oriente se han realizado grandes esfuerzos para ocupar la franja marítima, de un gran valor estratégico. Con unos 5 millones de habitantes, se ha desarrollado la agricultura y la ganadería para las necesidades de la población; se explota el carbón, el hierro, el oro y el petróleo (Sajalin); se ha instalado la siderurgia en Komsomolsk, industria de bienes de equipo en Jabarost, industria de pesca en otros puntos del litoral, donde destaca Vladivostok, el gran puerto pesquero y comercial ruso del Pacífico; fundada el 1869, en 1989 la ciudad censó 648.000 habitantes. También sobresale hoy la zona franca de Najodka, a donde llegan las inversiones americanas, japonesas y coreanas.

\section{c) Crisis y reformas económicas}

La relativa debilidad de Rusia procede, como todas las repúblicas ex-soviéticas, de su condición de estado multiétnico; no obstante, los rusos representan la inmensa mayoría (85\%) en la Federación Rusa; y 
en repúblicas de fuerte personalidad étnica los rusos suponen también un alto porcentaje; por ejemplo, en Carelia hay $73 \%$ de rusos y $10 \%$ de carelios; en Buriatia, $70 \%$ de rusos y $24 \%$ de buriatos; en Yakutia, $50 \%$ de rusos y $33 \%$ de yakutios. En algunas repúblicas no llegan al $50 \%$, como en Tatarstán, donde el $48 \%$ son tártaros y el $39 \%$ rusos, pero éstos son mayoría en las ciudades. También en las repúblicas nor-caucásicas la presencia rusa es muy débil, debido a la hostilidad tradicional de la población autóctona. Con la guerra de Chechenia y la agitación de los conflictos étnicos en esta zona cientos de miles de rusos han emigrado ya de estas repúblicas.

En la constitución aprobada en diciembre de 1993, la Federación Rusa está integrada por 89 territorios; unos son provincias y otros, repúblicas. Representantes de estos territorios constituyen el Consejo de la $\mathrm{Fe}$ deración que es la Cámara Alta del Parlamento y tiene la función de controlar las leyes y el presupuesto. La dependencia financiera de muchas repúblicas respecto al gobierno central constituye un freno a las tendencias separatistas de algunas de ellas.

En algunos casos, se tiene en cuenta la especificidad económica o étnica de algunas de ellas y se les concede un trato especial, como ha sucedido con Tatarstán, en la región del Volga, que puede establecer relaciones directas con el extranjero y adherirse a organismos internacionales; igualmente se ha llegado a un acuerdo especial con Bachkorstán, en Siberia Occidental. Sin embargo, no se logró evitar el conflicto con Chechenia, en el Norte del Cáucaso, que se declaró independiente y provocó la intervención brutal del ejército ruso.

Desde la desaparición del sistema socialista de planificación, la autonomía económica de las provincias y repúblicas es muy grande y las autoridades locales adoptan las medidas que creen más adecuadas para incentivar la producción. Así, unas han avanzado más hacia la economía de mercado, con una mayor liberalización, mientras que otras mantienen las medidas proteccionistas que frenan el ritmo de las reformas.f Sin embargo, para defenderse mejor del centralismo de Moscú, muchas provincias y regiones han formado asociaciones, como la Asociación de las Provincias del Centro, la de las Tierras Negras, la de las Provincias y Regiones del Volga, la del Gran Ural, etc.

Respecto a la reforma económica, Rusia se halla inmersa en una profunda crisis. Desde 1990, el PNB ha descendido en más del $50 \%$, la producción industrial, en más del $30 \%$ y el nivel de vida de la población se ha reducido casi a la mitad, situándose un tercio de las familias por debajo del mínimo vital; otro tercio dedica el $80 \%$ de sus ingresos a la alimentación. Se calcula que el indice de paro llegará en 1995 al 15\%. 
La autonomía de las empresas y la liberalización de precios, en vez de dar como resultado la creación del mercado, lo que hizo fue favorecer la formación de monopolios y provocar el caos en las relaciones entre proveedores y clientes. Esta desarticulación de las relaciones comerciales entre las empresas y la caída de la demanda han llevado a la infrautilización de la capacidad productiva, que en 1994 llega al $67 \%$ en el sector de la energía, al $60 \%$ en la metalurgia, al $54 \%$ en metalquímica y al $48 \%$ en la química.

La privatización del comercio y de los servicios ha progresado rápidamente, gestionada por las autoridades provinciales y locales; en 1994 afectaba al $70 \%$ del total.

En la agricultura no ha avanzado como se esperaba/La descapitalización del campesinado no ha permitido pasar gran cantidad de tierras a la gestión privada. Las explotaciones colectivas siguen ocupando el $88 \%$ de la superficie cultivada y dan empleo a más de 8 millones de trabajadores a tiempo completo (Kerblay, B., 1994, p. 190). Los koljoses y sovjoses se han convertido en asociaciones de productores $\angle$ los campesinos pueden recibir hasta 20 hectáreas gratis, pero no pueden llevar su explotación por si sólos, debido a que ni la mecanización ni los fertilizantes se pueden conseguir fuera de las cooperativas. Éstas aseguran el alojamiento y la seguridad social de un campesinado envejecido, con un tercio en edad de jubilación. Han aumentado sustancialmente los huertos familiares y las parcelas de los habitantes de las ciudades que, en tiempos de escasez, constituyen un complemento esencial, sobre todo, de patatas, legumbres y frutalesf Las explotaciones privadas de orientación comercial han llegado a 350.000 en 1994 y proporcionan el 5\% de la producción cerealista. Por lo tanto, el Estado todavía conserva el monopolio de las grandes producciones de cereales.

Las dificultades de la agricultura no se sitúan en el terreno de la producción, sino en el deficiente aprovisionamiento de maquinaria y de fertilizantes y en los aspectos de comercialización, de transporte y de refrigeración; estos últimos provocan la pérdida del 10 al $20 \%$ de las cosechas.

Por su parte, las grandes empresas industriales se han transformado en sociedades por acciones, que en 1994 representan el $70 \%$ del capital industrial. Pero, en realidad no se puede hablar propiamente de privatización, ya que las acciones están repartidas entre los trabajadores, y el Estado se reserva un lote suficiente para poder mantener el control. En otros casos, la empresa sigue controlada por los antiguos directores que han podido hacerse con la mayor parte de las acciones, debido al sistema de relaciones personales gestadas en los tiempos del socialismo. En las 
ramas más rentables el capital extranjero ha adquirido parte del capital, creándose numerosas empresas mixtas. Para favorecer las inversiones procedentes del exterior, Rusia ha creado zonas francas, entre las que sobresalen las de Kaliningrado, en el Báltico, y la de Extremo Oriente, en el Pacífico. Sin embargo, hasta el momento, no se ha formado una clase empresarial que pudiera impulsar el proceso de reformas. El poder real de la industria sigue en manos del Estado que, además, posee todas las empresas de la industrial militar.

\section{UCRANIA Y BIELORRUSIA, LAS DOS REPÚBLICAS ESLAVAS INSEPARABLES DE LA GRAN POTENCIA}

Regiones fronterizas del imperio de los zares, una parte de ambas repúblicas ha estado sometida a la influencia de Polonia. En 1939 las fronteras se desplazaron hacia el Oeste y en 1954 Crimea, península que pertenecía a Rusia, pasó a depender administrativamente de Ucrania.

Bielorrusia tiene 10,4 mill. de habs. en 1993 y Ucrania 52; en total, 62 mill. que equivalen a una cuarta parte de la población de la CEI. Mientras que Bielorrusia tiene población muy homogénea, con sólo $12 \%$ de rusos, en Ucrania etnia y religión enfrentan el Oeste, ucraniano y católico, con el Este, rusificado y ortodoxo; entre la población de Ucrania hay, además de eslavos, otras nacionalidades, como polacos, moldavos, rumanos, tártaros, etc.

Participe del desarrollo de la URSS europea, Bielorrusia y Ucrania están dotadas de unas economías diversificadas y de un territorio bien organizado, en el que se sitúan siete de las veintitrés aglomeraciones millonarias de la CEl. Las infraestructuras de transporte, de comercio y de servicios son comparables a las de Rusia europea.

a) Bielorrusia tiene unas aptitudes agrícolas mediocres (tierras frías, productoras de patatas, centeno y lino), pero ha conseguido modernizar su ganadería; proporciona el $5 \%$ de la producción agropecuaria de la CEI. Sus tierras de cultivo se han visto afectadas por las radiaciones de Chernobil: en 1986 el porcentaje de tierras agrícolas era del $45 \%$ del total y en 1983 había descendido al 35\%. La privatización de la agricultura avanza a un ritmo moderado, pasando del $27 \%$ en 1991 al $45 \%$ en 1993.

Con escasos recursos naturales (importa de Rusia el $90 \%$ de la energía), es menos industrial que Ucrania: su producción equivale al $4 \%$ del total de la CEI. Sin embargo, su sistema industrial está muy integrado con el de Rusia y la región de Minks forma parte del llamado "creciente fértil tecnológico" que se prolonga por el litoral báltico hasta San Petersburgo. 
Fabrica camiones y piezas de automóviles y se ha especializado en tecnología punta (ordenadores y material informático).

Con un equipamiento industrial obsoleto, la producción de la industria ha descendido en más de un $30 \%$ entre 1992 y 1993 . Todavia mantiene el $70 \%$ de los empleos en el sector público y la independencia de las ex-repúblicas soviéticas ha repercutido en Bielorrusia muy negativamente/Esta es la razón que le ha llevado a estrechar sus relaciones con Rusia: en el referendum de mayo de 1995 el $83 \%$ de la población apoyó la integración económica completa con la Federación Rusa, otorgando, además, al idioma ruso el mismo estatuto que al bielorruso. Se ha llegado, así, a una relación con Rusia muy parecida a la existente en tiempos de la URSS. La capital Minks ha experimentado un fuerte crecimiento en las últimas décadas: de medio millón de habitantes en 1958 ha pasado a 1,7 en 1991.

b) Ucrania es económicamente un país privilegiado (mapas de las figuras 3,4 y 5). Con un territorio más extenso y más poblado que España, participa con el $18 \%$ de la producción agrícola, el $17 \%$ de la industrial y el $25 \%$ del carbón/Uno de sus pilares es la agricultura, por la excepcional calidad de sus tierras: 150 mill. de ha; $2 / 3$ de la superficie total se halla cultivada. No sólo es el granero de trigo ( $1 / 2$ del que se produce en la CEI); también lo es de maíz, remolacha azucarera (3/4) y de girasol. Los rendimientos son muy altos en las tierras negras; la agroindustria ha desarrollado la elaboración de azúcar, cuero, aceite, conservas de carne, etc.

Ucrania es también una gran región industrial, desarrollada sobre la base de unos recursos naturales importantes, aunque hoy en descenso: su producción de carbón es mayor que las del Ruhr; cuenta también con gas (1/3 de la producción de la CEI); tiene hierro (Kriboi-Rog) y manganeso (Nikopol). El conjunto Donetsk-Dniéper, corazón industrial del imperio ruso antes de 1917, es hoy un "país negro» hipertrofiado. A la actividad siderúrgica y a la producción de metales no ferrosos y de armamento, concentrada sobre la cuenca hullera de Donbass, se ha añadido la industria química basada en el gas descubierto en el norte de la cuenca.

Se distinguen dos núcleos industriales importantes: al Este, con Donetsk, ciudad del acero ( $37 \%$ de la producción de la CEI), Lugansk, con material ferroviario. Al Oeste, sobre la energía hidroeléctrica del Dniéper, ha surgido Zaporoje, principal centro de la CEI en ferroaleaciones y aluminio, y Dniepropétrovsk, ciudad de siderurgia, con aceros especiales, y de construcciones mecánicas.

La región occidental es más agrícola y las industrias diversificadas están más dispersas. Sin embargo, su fachada marítima es la más activa de todas las de la ex-Unión Soviética, con grandes puertos, como 
Nikolaiev, Odessa, Sebastopol y Yalta. En el borde del mar de Azov, en Jdanov se ha instalado una siderurgia y construcciones navales, y en la ribera del mar Negro ha surgido una importante actividad turística.

Un gran número de ciudades entre 100.000 y 1.000 .000 de habitantes se distribuye por todo el territorio, pero ninguna domina verdaderamente la región. La modernización de la agricultura va acompañada del éxodo rural y el estancamiento de la industria pesada se compensa con el progreso de las industrias más modernas, sobre todo en Kiev; esta ciudad, adelantándose a Jarkov, funciona con extraordinaria potencia, creando nuevas industrias y laboratorios, atrayendo a la población y desarrollando las actividades terciarias (1959, 1,1 mill. de habs; 1991, 2,6 mill.). Tercera aglomeración urbana de la CEl, la capitalidad de la Ucrania independiente no hará más que potenciar esta tendencia.

Para Rusia la asociación con estos dos Estados eslavos es de suma importancia, no sólo por ser industrial y tecnológicamente avanzadas, sino también porque constituyen la puerta entre Rusia y Europa centro-oriental, cuyos países pueden un día formar parte de la Unión Europea. Además, a través de Ucrania, consigue la salida a un mar cálido, tanto tiempo anhelado en siglos pasados.

- También para Bielorrusia y Ucrania la asociación con Rusia tiene grandes ventajas; por encima de todo, las tres tienen una economía muy interrelacionada, que no es fácil separar; estructuralmente, las dos se hallan cautivas de Rusia. Mientras que Bielorrusia es una firme partidaria de la integración fuerte, Ucrania es muy reacia a estrechar las relaciones con su gran vecino/Sin embargo, no ha podido evitar ser miembro de la Unión Económica, con la esperanza de sacar a flote su economía; agobiada por la caída de la producción industrial, en 1994 está al borde de la ruina. En 1993 todas las grandes producciones ucranianas habían sufrido un fuerte descenso: los cereales de 53 mill. de t en 1990 a 35 mill. en 1993; la remolacha azucarera, de 44 mill. de t a 28; la producción de carne, de 4,3 mill. de t a 3,5 mill.

A pesar de la fuerte crisis que está axfisiando a su sistema industrial, Ucrania todavía es en 1993 una gran potencia minera e industrial. Es $7^{\circ}$ productor mundial de carbón con 118 mill. de t (165 mill. en 1990, 1/4 del carbón soviético); 20.000 mill. de $\mathrm{m} 3$ de gas natural (13ำ productor mundial) y 4 mill. de t de petróleo. En 1993, la producción industrial se ha reducido a las $2 / 3$ de la existente en 1990, acusando la existencia de un equipamiento envejecido y el excesivo consumo de energía.

Además de la dependencia energética y del fuerte endeudamiento respecto a Rusia, el problema geopolítico de Ucrania consiste en que el $20 \%$ de la población ucraniana (11 mill.) es de origen ruso y vive en la parte 
oriental del país, con centro en Jarkov; cualquier intento de una excesiva independencia respecto a Rusia, se vería frenado por esta importante minoría que podría llegar a escindir en dos partes el territorio ucraniano.

\section{LOS PEQUEÑOS ESTADOS DEL FRENTE OCCIDENTAL: LA DIFICIL INDEPENDENCIA ECONÓMICA}

Las repúblicas más pequeñas de la ex-Unión Soviética están situadas en su extremo más occidental. Tanto los Estados bálticos -Estonia, Letonia y Lituania-, como Moldavia fueron anexionadas en la última expansión soviética hacia el Oeste, en 1940; desde entonces, las poblaciones autóctonas no eslavas han mantenido un fuerte sentimiento antirruso. El desarrollo industrial impulsado por la planificación central ha ido acompañado de una importante inmigración de población rusa, instalada en las ciudades y en los centros industriales.

Con la desintegración de la URSS, las tres repúblicas bálticas han conseguido la independencia y han dado la espalda a Rusia y a la CEl; Moldavia, por el contrario, ha terminado por integrarse en la estructura de la CEI, obligada por el problema surgido con su actual minoría rusa.

a) Presentados como escaparate del socialismo, Estonia, Letonia y Lituania recibieron grandes inversiones de la URSS y llegaron a ser las repúblicas más desarrolladas y de mayor renta por habitante. En un paisaje de llanura, los suelos son pobres; no tienen materias primas, pero disponen de una fachada marítima sin hielos, donde han surgido puertos muy activos, como Tallin y sobre todo Riga (1 millón de habs. en 1991), que hoy es un importante puerto de entrada y salida de la CEI. Las tres repúblicas han conseguido buenos rendimientos agrícolas y una ganadería muy desarrollada ( $70 \%$ del valor total de la agricultura), con gran producción lechera. Igualmente, se ha montado una industria de alta calidad (electrónica, electrodomésticos, maquinaria industrial, agroalimentación, etc.) y se han construido buenas infraestructuras de transporte. Las tres capitales (Tallin, Riga y Vilnius) son las que concentran la mayor parte de la industria.

A pesar de su aparente homogeneidad, entre los tres Estados existen importantes diferencias étnicas y religiosas: Estonia, con 1,5 mill. de habs. en 1993 , de los que sólo el $60 \%$ son estonios, habla un idioma fino-ugrio y es de religión protestante; Letonia, tiene 2,6 mill. de habs., el $55 \%$ son letones y su religión es también protestante, y Lituania, con 3,7 mill. de hab., es de mayoría católica y el $80 \%$ son lituanos, teniendo una presencia escasa de rusos $(10 \%)$ y una minoría de polacos $(7 \%)$. 
Estas son las tres únicas repúblicas ex-soviéticas que han permanecido fuera de la CEI. Han optado por restablecer las viejas relaciones comerciales con los países nórdicos, confiando en que el mar Báltico se convierta en un espacio de cooperación regional, en el que ellas queden integradas Sin embargo, su dependencia económica de Rusia sigue siendo absoluta; de ella reciben casi toda la energía y las materias primas, y con ella realizan entre el 60 y el $70 \%$ de los intercambios.

Estas circunstancias permiten deducir que su relación con Rusia seguirá siendo estrecha, aunque no estén integradas en la CEl. Ademas, también Rusia tiene intereses en los Estados bálticos, no sólo por ser territorios desarrollados, sino porque allí vive un gran número de rusos, sobre todo en Estonia y Letonia ( $30 \%$ y $37 \%$ de su población, respectivamente), que hoy se han convertido en minoría, discriminada en el derecho de votar y en el uso de su lengua.

En 1993, las tres repúblicas empiezan a dar señales de estabilización, tras un trienio catastrófico en la evolución de su economía, en el que se ha producido un fuerte descenso, tanto de la producción vegetal $(50 \%)$ y animal (32\%), como en la industrial (40-50\%); ello se ha debido, fundamentalmente, a su ruptura con Rusia y a la paralización de muchas empresas estatales, donde la mayoría de la técnica y de los empleados eran rusos. La transición ha sido rápida y la privatización está muy avanzada, sobre todo en la agricultura, donde han surgido muchos pequeños propietarios. Las monedas están consolidadas y la inflación controlada. La importante inversión extranjera, rusa y alemana, ha impulsado la modernización de la economía que hoy está ya muy próxima a la occidental.

b) El caso de Moldavia es muy distinto. Territorio rumano antes de la Segunda Guerra Mundial, es un país de colinas y llanuras, de clima relativamente benigno y tierras negras, entre el Dniéster y el Prut, y se halla enclavado entre Rumania y Ucrania. Su desarrollo se basa en la agricultura y en la ganaderia, principales actividades del país. Entre todas las repúblicas ex-soviéticas, Moldavia es la principal suministradora de frutas y produce el $33 \%$ del vino de la ex-URSS; el sector agroalimentario representa $2 / 3$ de la producción nacional.

Sin embargo, la república presenta una cierta complejidad geopolítica. De los 4,4 mill. de habs. en 1993 , el $65 \%$ son de origen, lengua y cultura rumana. Ello explica que con la independencia Moldavia intentara llevar a cabo su unión con Rumania; en la Constitución se expresa el derecho del pueblo moldavo de "reencontrar el espacio histórico y étnico de su formación". La situación se complica, pues Moldavia reivindica a Ucrania dos territorios fronterizos: uno, al Norte, la Bucovina y otro, al Sur, una parte de la región de Odessa, donde una importante minoría son rusófonos. 
Ademas, dentro de sus límites le han surgido dos repúblicas secesionistas: la rusa del Transdniéster, con capital en Tiraspol, y la de los gagauzos ( $3,5 \%$ del total), población turcófona, con centro en la ciudad de Komiat (mapa de la Fig. 6). La que mayor peligro encierra es la minoría rusófona ( $14 \%$ de ucranianos y $13 \%$ de rusos) que controla el $15 \%$ de la superficie del país y proporciona un tercio de la producción agrícola e industrial.

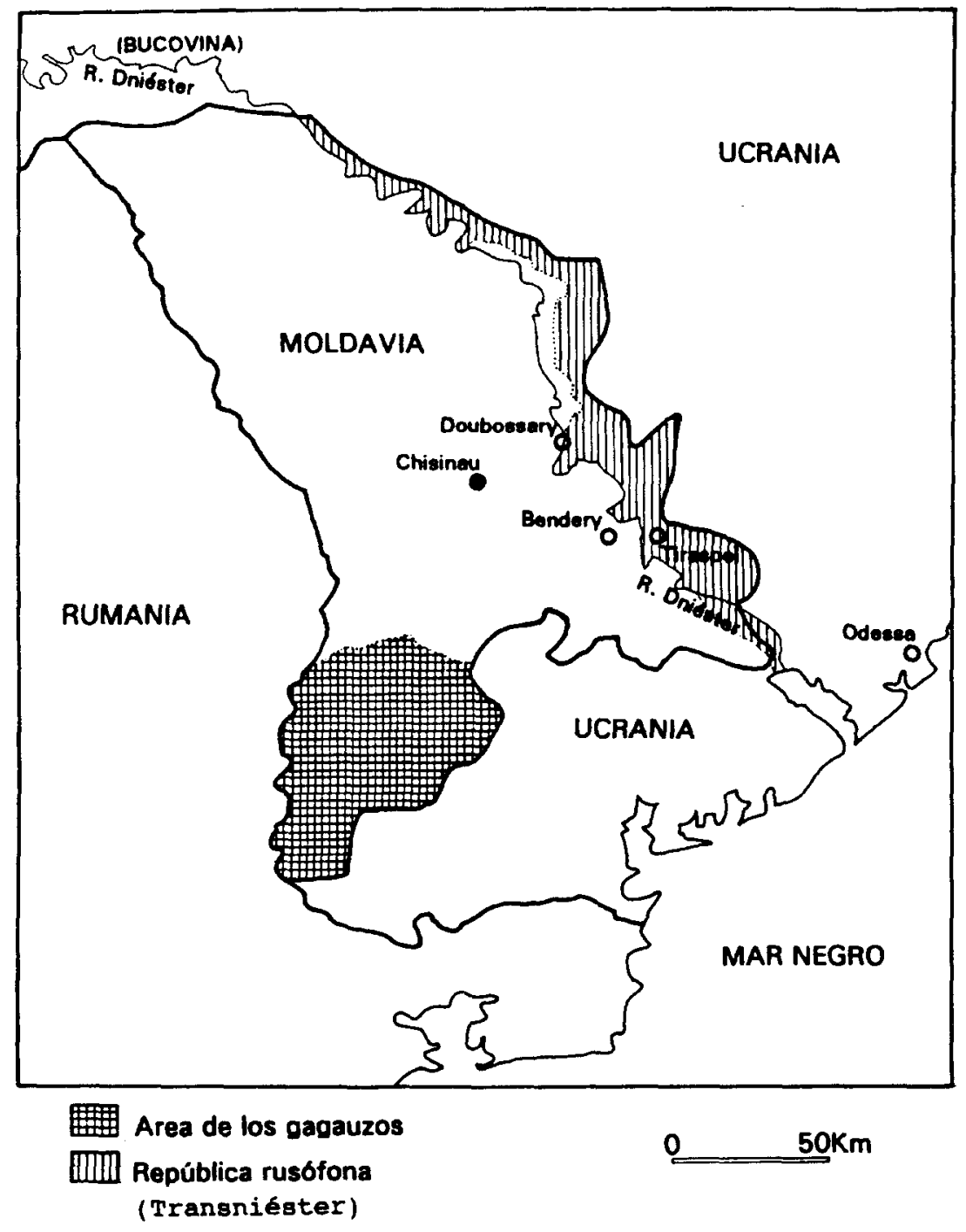

Figura 6. Minorias étnicas en Moldavia. 
Al principio, Moldavia se resistió a la integración en la CEl; ha sido una de las repúblicas más hostiles a la Comunidad; pero, al final, ante la presión de los rusos y el aislamiento internacional y ante el peligro de escisión territorial, ha terminado por entrar a formar parte de la nueva asociación de repúblicas ex-soviéticas.

Los problemas étnicos y el conflicto bélico de 1992 hicieron que la producción agrícola e industrial descendiese en 1993 al 50\% respecto a 1990. Predomina la agricultura $(60 \%)$, con maíz, trigo, remolacha azucarera y vid, sobre la ganadería porcina y ovina (30\%). En 1992 se inició un plan de privatización que ha puesto ya el $20 \%$ de las tierras en manos de particulares; éstos obtienen en 1994 el $40 \%$ del valor de la producción agrícola. El plan prevé que sólo el $6 \%$ de la tierras seguirá siendo de propiedad estatal.

\section{REPÚBLICAS TRANSCAUCÁSICAS: CRISIS ECONÓMICA PROFUNDA}

Las repúblicas del Cáucaso, junto con las de Asia Central, constituyen el gran Sur de la antigua Unión Soviética y de la actual CEI. Desde el mar Negro hasta la cuenca alta del Oby, se extienden las ocho repúblicas meridionales, con problemas sociales y territoriales de difícil solución: pueblos no eslavos con viejas rivalidades, territorios conquistados por Rusia, economías pobres, diferencias religiosas, conflictos étnicos; son países cálidos, con graves problemas de aridez; los pueblos incorporados tardíamente y por la fuerza al imperio ruso mantienen su idioma propio y su cultura tradicional musulmana, hoy revitalizada. Su alta natalidad determina el fuerte crecimiento natural que, a su vez, agrava el problema de la pobreza y de la crisis económica.

En esta periferia meridional la industria apenas se ha desarrollado, continuando el predominio agrícola y exportando productos poco elaborados, con lo que la dependencia respecto a las otras repúblicas ex-soviéticas, especialmente de Rusia y de Ucrania, es muy fuerte.

La complejidad del relieve y los contrastes climáticos hacen del Cáucaso una región muy complicada, desde el punto de vista de su organización territorial. Si a ello añadimos los más de 30 grupos étnicos entre los 16 mill. de habs., instalados en esta montaña-refugio, sobre unos 1.500 $\mathrm{km}$ de longitud, podremos entender las dificultades para lograr una convivencia pacífica. Región de contacto entre Europa y Asia, la lucha por la supervivencia en estos territorios entre etnias, lenguas y religiones han 
suscitado odios feroces, muy dificiles de eliminar. Siempre ha sido un avispero y, desde que Rusia los conquistó, no han dejado de ser un rompecabezas hasta ahora no resuelto (mapa de la fig. 7).

La URSS creyó haber encontrado una solución al establecer un mosaico de repúblicas, unas federadas y otras autónomas dentro de las federadas, tratando de satisfacer las ansias de autonomia de los grupos y culturas mayoritarios. Las situadas al Norte del Cáucaso quedaron integradas en la Federación Rusa; entre ellas figuran las de Osetia del Norte, Ingusia y Chechenia. En el Sur de la cadena se delimitaron tres repúblicas federadas que se suelen denominar transcaucásicas: Georgia, al Oeste; Armenia, en el centro, y Azerbaiyán, en el Este.

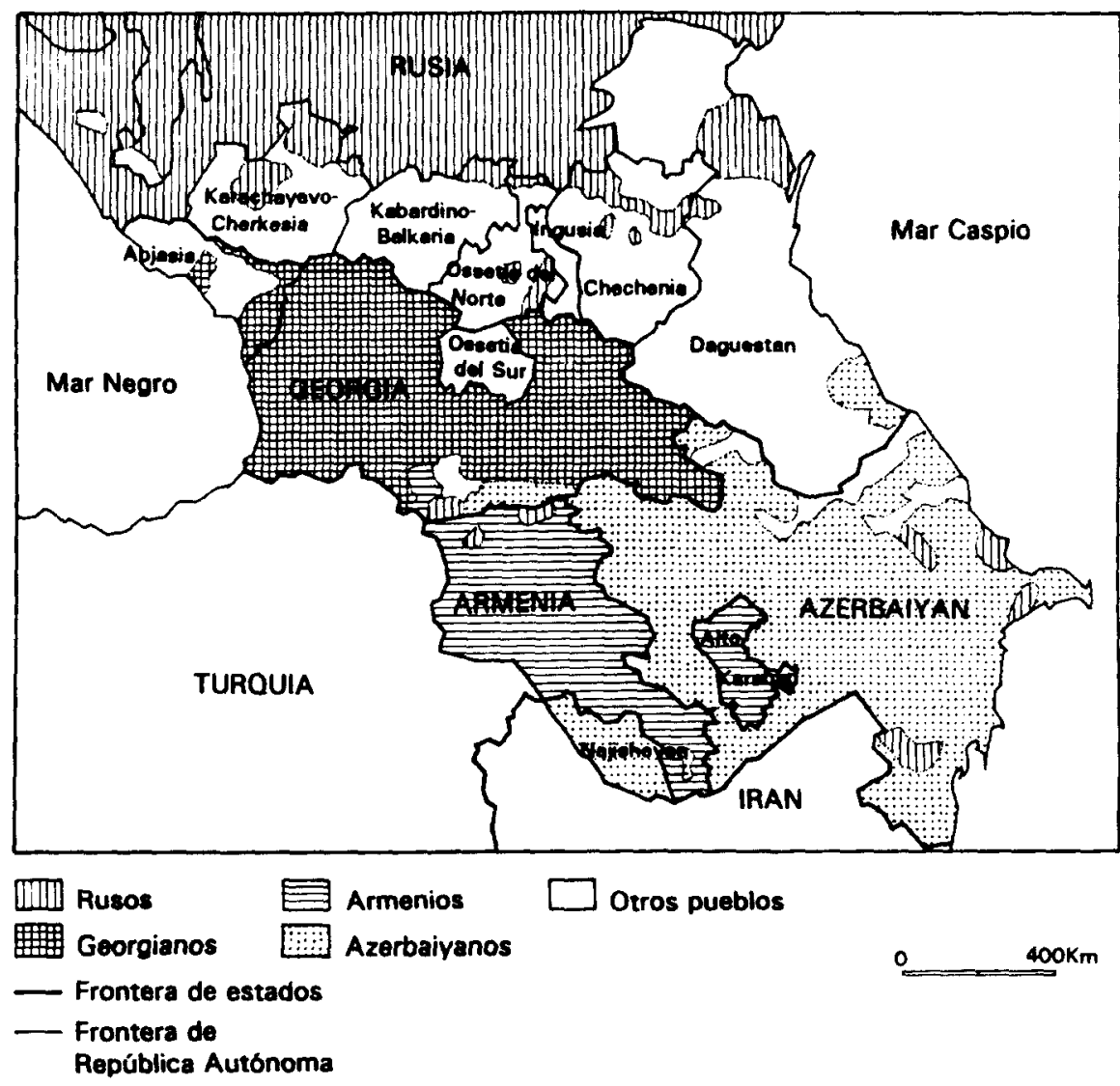

Figura 7. Estados, Repüblicas y grupos étnicos en el Cáucaso. 
En las últimas décadas de la URSS, su economía parecia haberse modernizado y diversificado. Sin embargo, con la desintegración de la Unión y las guerras que han castigado a estos países, sus economías han sufrido de manera especial la crisis económica generalizada, cuyo reflejo es la fuerte reducción del Producto Nacional Bruto y el descenso de las producciones agricola e industrial.

\section{CUADRO 4. EVOLUCIÓN DE ALGUNOS INDICADORES ECONÓMICOS}

\begin{tabular}{lrrrrrr}
\hline & \multicolumn{2}{c}{ GEORGIA } & \multicolumn{2}{c}{ ARMENIA } & \multicolumn{2}{c}{ AZERBAIYÁN } \\
\hline PRODUCCIÓN & 1989 & 1993 & 1989 & 1993 & 1989 & 1993 \\
\hline P.I.B. & 100 & 30 & 100 & 38 & 100 & 50 \\
P.I.B./hab. & 1.900 & 730 & 1.780 & 910 & 1.750 & 800 \\
Prod. industrial & 100 & 35 & 100 & 39 & 100 & 59 \\
Prod. agraria & 100 & 55 & 100 & 63 & 100 & 70 \\
\hline
\end{tabular}

Fuente: Atlaseco (1995) e Instituto de Europa Oriental

a) Georgia es una de las repúblicas privilegiadas de la antigua Unión Soviética. Con un clima subtropical húmedo, disfruta de una economía diversificada; su población de 5,5 mill. de habs. ( $70 \%$ georgianos) equivale al $2 \%$ de la CEI y asegura el $1,7 \%$ de la producción interna de la Comunidad.

El relieve montañoso permite diferenciar las regiones altas, con predominio de ganadería ovina, y los valles occidentales y llanuras litorales, con un policultivo rico e intensivo de cítricos, té, vid, tabaco y ganadería bovina. Georgia produce el $90 \%$ del té y de los agrios de la actual CEI, además de otros frutales. Destaca por su especial prosperidad agrícola la fachada del mar Negro, la vieja Cólquida de los griegos, que en las últimas décadas tuvo un importante desarrollo turístico.

Georgia cuenta con algunos recursos naturales, como el manganeso, y los puertos sobre el mar Negro han atraído algunas industrias dispersas. Georgia llegó a ser una de las repúblicas soviéticas con mayor renta por habitante; de las otras repúblicas sólo recibía el $25 \%$ de los productos; parecía ser autosuficiente (excepto en la energía) y, al declararse independiente, confiaba en la supervivencia económica. Pronto surgió un nacionalismo radical que rechazó su integración en la Comunidad de Estados Independientes.

Sin embargo, no tardaron en estallar graves tensiones que desembocaron en una guerra civil. En su interior existen dos repúblicas autónomas: 
Ossetia del Sur, que desea su unión con Ossetia del Norte, y Abjasia, poblada por georgianos musulmanes enfrentados con el resto de georgianos cristianos ortodoxos. Abjasia, una rica región junto al mar Negro, se declaró independiente y mantuvo la guerra con Georgia hasta que esta solicitó la intervención a su favor del ejército ruso. A cambio de esta ayuda, Georgia estrechó los lazos con Rusia, incorporándose a la CEI en octubre de 1993, participando en todas las instituciones de integración regional y convirtiendose en un buen aliado de Rusia.

Los conflictos étnicos y la guerra civil han provocado grandes trastornos en la economía, con un fuerte retroceso de las producciones y destrucción de infraestructuras, difíciles de recuperar. En 1993, la superficie cultivada se había reducido al $50 \%$, la producción de acero, hierro y productos siderúrgicos fue el $62 \%$ respecto a 1989 . La industria agroalimentaria (cerveza, vino, champagne, coñac y vodka) ha sufrido menos, pero la pequeña industria moderna instalada en las últimas décadas de la URSS sólo funcionaba en 1993 al 30\% de su capacidad. La catástrofe económica se refleja en el hecho de que el P.I.B. era en ese año apenas 1/3 del que tuvo en 1990.

Hoy, en 1995, la economía de Georgia es muy abierta (el comercio exterior supone el $40 \%$ del P.I.B.) y el $90 \%$ de las importaciones y exportaciones proviene y se dirige a los Estados de la CEI. No es de extrañar que, después de una experiencia tan catastrófica, Rusia se haya convertido en su mejor aliado y su incorporación a la CEI sea la mejor garantía de la paz y de la estabilidad.

b) Armenia, con $30.000 \mathrm{~km}^{2}$, es la más pequeña de las tres repúblicas transcaucásicas. Está situada en la parte mas agreste de la cordillera y se halla poblada por 3,3 mill. de habs, alcanzando una alta densidad de población (110 habs $/ \mathrm{km}^{2}$ ). En realidad, la Armenia actual es sólo la parte oriental de la Gran Armenia Histórica, cuya parte occidental pertenece a Irán y Turquía.

Los armenios son un pueblo antiquísimo, cuya lengua se halla próxima a los orígenes de la indoeuropea. Tradicionalmente, han sido sedentarios y han sufrido las masacres provocadas por los nómadas kurdos. Lo inhóspito de su territorio y el acoso constante de otros pueblos han impulsado una intensa corriente emigratoria a Europa Occidental y a EEUU. Otro rasgo de originalidad radica en su religión cristiana primitiva que ni es de rito católico ni ortodoxo.

Confinada en este espacio montañés, Armenia es un territorio pobre, dedicado a la ganadería ovina y con algunos valles abrigados donde se cultiva la vid, tabaco, flores, frutales y hortalizas. No dispone de recursos minerales, excepto de cobre y canteras de mármol y basalto. El carácter montañoso ha favorecido la construcción en tiempos de la Unión Soviética 
de centrales hidroeléctricas; también se construyó una central nuclear que favoreció la instalación de industrias químicas, de aluminio y metales raros (selenio y telurio). La central se cerró tras el fuerte terremoto que se registró en 1988 y las industrias que proporcionan el $72 \%$ de las exportaciones (metales, maquinaria industrial, productos textiles, calzado, industria agroalimentaria) se aprovisionan de energía importada de Rusia, ya que el gasoducto procedente de azerbaiyán se cerró en 1991. Sólo dispone de energía hidroeléctrica y necesita importar las $2 / 3$ partes de la energía que consume; debido a esta necesidad, proyecta reabrir la central nuclear y construir un gasoducto desde Irán.

Armenia es una firme defensora de la integración de las repúblicas exsoviéticas y mantiene unas estrechas relaciones con Rusia. Ello es fácil de explicar, debido a la tensa rivalidad y enfrentamiento con su vecina Azerbaiyán, que le puede imponer un bloqueo total, tanto energético como de mercancías.

La raíz de este enfrentamiento reside en la vieja enemistad entre armenios, cristianos, y azeríes, musulmanes. El conflicto, repetido en diversas ocasiones históricas, ha estallado con ocasión del problema del Alto Rarabaj, enclave de 150.000 armenios puesto bajo la jurisdicción de Azerbaiyán desde 1923.

La supresión del estatuto de autonomía de este enclave en septiembre de 1991 radicalizó la reivindicación armenia del territorio, provocando una guerra entre ambas repúblicas que terminó con la mediación rusa. Sus economías se han visto muy resentidas y los conflictos interétnicos han obligado a desplazarse a 200.000 armenios de Azerbaiyán y a 150.000 azeries de Armenia. En 1992, año de la guerra y del bloqueo, la renta nacional armenia retrocedió un $40 \%$ y la producción industrial, un $50 \%$. En estas condiciones, su independencia económica parece absolutamente inviable, debido a su situación de aislamiento y al bloqueo de su vecino, convertido hoy en su enemigo. La única alternativa que a Armenia le queda es su estrecha relación con Rusia y su total integración en la CEI.

c) Azerbaiyán ocupa una depresión abierta hacia el mar Caspio, que sufre altos índices de aridez. Este pais ha basado su desarrollo en el petróleo y en el regadío.

Explotado desde 1873, el yacimiento petrolífero de Bakú era en 1900 el primero del mundo; hasta los años 40 proporcionaba el $75 \%$ del petroleo soviético. En 1970 la producción fue de 25 mill. de t y en 1993 sólo se extrajeron 11 mill. Esta reducción de la producción unos la atribuyen al agotamiento de los pozos; pero, otros la achacan al equipamiento ya envejecido, instalado a principios de los años 60 . De cualquier manera, el área de 
explotación avanza bajo el mar Caspio y hoy se confía en las técnicas occidentales que podrían extraer petróleo de capas más profundas y aumentar así la producción hasta el nivel conseguido a principios de los 70 .

Aprovechando esta fuente de energía, la industrialización se desarrolló pronto: centrales térmicas, industrias químicas, metalurgia y electromecánicas, material de sondeo, etc. La capacidad de refinado es de 20 mill. de t, aunque en 1993 sólo ha producido 12 mill. de t que exporta en su mayor parte.

Debido a la aridez de la depresión, la actividad agrícola tradicional es de cereales extensivos y ganadería ovina; pero, el control del agua procedente de la alta montaña ha permitido la creación de un extenso regadío, donde se cultiva algodón ( $20 \%$ de la producción agrícola), vid, tabaco, frutales y verduras; el algodón, a su vez, ha dado origen a una industria manufacturera de hilos y tejidos. La guerra con Armenia ha perjudicado gravemente la producción agrícola; sin embargo, la privatización se ha desarrollado con rapidez y en 1993 el $40 \%$ de los koljoses y sovjoses habian pasado ya a manos privadas.

Así que Azerbaiyán cuenta con una economía relativamente diversificada, pero con infraestructuras ya muy envejecidas. Un grave problema consiste en la imposibilidad de plantear una colaboración con los otros Estados caucásicos, especialmente con Armenia. De los 7 mill. de habs., el $80 \%$ son azeries, turcófonos y musulmanes chiitas; el $6 \%$ son armenios y rusos cristianos. Con la guerra, cientos de miles de armenios han emigrado de Azerbaiyán, lo mismo que los azeries que vivían en Armenia.

Este país quiere mantener buenas relaciones con Irán, donde viven ctros 5 millones de azeríes y se siente atraida por las repúblicas de Asia Central, debido a la común cultura islámica. Reacia, al principio, a su integración en la CEI, ha terminado por firmar todos los acuerdos de colaboración, con la esperanza de mejorar su deteriorada situación económica, recuperando su capacidad productiva, tanto en la agricultura como en la extracción y refinado de petróleo.

\section{LOS ESTADOS DE ASIA CENTRAL: EL RIESGO DE HUNDIRSE EN EL SUBDESARROLLO}

\section{a) El conjunto de Asia Central}

EI Asia Central Soviética, tras la desaparición de la URSS, se ha fragmentado en cinco Estados: Kazajstán, Kirguistán, Uzbekistán, Turkmenistán 
y Tayikistán. Con sus 4 mill. de $\mathrm{km}^{2}$, presenta serios problemas de integración en una economía y sociedad modernas. La lejanía del centro económico ruso - unos $3.000 \mathrm{~km}$ - se une a la fuerte especificidad natural y humana. Al Sur de las estepas kazajas se extiende la depresión aralo-caspiana, amplio conjunto territorial árido, anexo a las altas montañas del Sur. Valles, cuencas y oasis constituyen los medios de vida privilegiados.

Contra la aridez se ha luchado mediante una política de grandes obras hidráulicas en las montañas meridionales: en los valles del Amu-Daria y Syr-Daria se han puesto en regadío ocho millones de hectáreas (equivalentes a la extensión de Castilla-La Mancha). Otro grandioso proyecto de trasvase de las aguas del alto Irtys hacia las estepas de Kazajstán, que podria haber triplicado la superficie regada, fue paralizado en los años de Gorbachov.

Aquí, junto a los cursos de agua, florecieron viejas civilizaciones sedentarias que llegaron a su explendor en los siglos XII-XIV (Samarcanda, Bujara). Hoy, desde el punto de vista humano, los Estados de Asia Central se caracterizan también por la importancia del Islám y la demografía más dinámica que en el resto de las repúblicas ex-soviéticas. Los 52 mill. de habitantes, se distribuyen en densidades medias de $20 \mathrm{habs} / \mathrm{km}^{2}$, aunque en las zonas regadas se alcanzan de 100 a $200 \mathrm{habs} / \mathrm{km}^{2}$; a pesar de las altas tasas de natalidad (superiores a 30 por mil), no existe emigración y la población se acumula en las zonas rurales, donde se ha pasado de 9 mill. de habs. en 1959 a 11 mill. en 1979. Igualmente, las ciudades han crecido también de una forma rápida.

En estas repúblicas hubo una importante inmigración rusa y eslava que se instaló en las ciudades; sin embargo, sólo han llegado a ser mayoría en Kazajstán. En las demás repúblicas musulmanas el grupo de eslavos, sobre todo rusos, ha representado entre el $10 \%$ y el $25 \%$. En la actualidad se está produciendo una corriente de retornos, por lo que en los próximos años este porcentaje habrá disminuido sensiblemente.

El potencial de conflictos nacionales y territoriales es inmenso, pues las fronteras trazadas en los años 20 por Stalin son artificiales, ya que anteriormente no existía el concepto de Estado territorial, similar al europeo. Los tayicos son iranófonos, mientras que los demás son turcófonos, los kazajos y kirguises son tradicionalmente nómadas, mientras que los uzbecos son sedentarios; Samarcanda y Bujara, grandes centros históricos tayicos, se hallan en territorio uzbeco, etc.

La sociedad de estas regiones estuvo dominada por la estructura del partido comunista y las élites locales económicas e intelectuales están 
poco desarrolladas, pues los cuadros políticos soviéticos estaban formados por inmigrantes rusos.

En el conjunto del Asia Central la actividad agrícola es la dominante: ganadería ovina extensiva en las montañas del Sur y en las estepas áridas, cultivos delicados de frutales y hortalizas en los regadíos tradicionales; los grandes proyectos socialistas se han concretado en los regadíos y en la producción del algodón, que sólo parcialmente se transforma en la región. Los recursos económicos se completan con una pequeña producción de petróleo, gas y algunos metales. Con la excepción del Norte de Kazajstán, muy rusificado, la industria sigue siendo embrionaria, destacándose sólo las grandes ciudades como centros de industrias de bienes de consumo.

Se mantienen, pues, las actividades y los modos de vida tradicionales, siendo los territorios con mayor población rural y menor indice de industrialización de toda la desaparecida URSS. Las metrópolis regionales que han experimentado un fuerte crecimiento son Taskent, con 900.000 habs. en 1959 y 2,1 mill. en 1991, y Alma-Ata, con 500.000 y 1,2 mill. de habitantes respectivamente.

El gran peligro que acecha a estos países es la posible ruptura social, no sólo entre etnias distintas, sino también entre islamistas radicales y no islamistas, entre anti-rusos y pro-rusos. La crisis económica derivada del proceso actual de descolonización agudiza las diferencias sociales que se mezclan con las divisiones étnicas y religiosas. Esto podría arrojar a estas sociedades al fondo del subdesarrollo y provocar una quiebra social parecida a la que se está produciendo en Argelia. De aqui, el alto grado de incertidumbre y de la inquietud que provoca la actual transición postcomunista. Su integración en la CEI, con ser un hecho tranquilizador, no ha eliminado totalmente este peligro, ya que los conflictos interétnicos y territoriales no han sido superados.

b) Kazajstán, segundo país en extensión después de Rusia, es el más rico y el más industrializado de todos los Estados de Asia Central. Con 2,7 mill. de $\mathrm{Km}^{2}$ y 17,2 mill. de habitantes en 1993, aporta el $3 \%$ de la producción industrial de la CEI y el $6 \%$ de la producción agrícola. Desde 1950, la república ha aumentado el número de habitantes en 11 millones. Ello se debe a la fuerte natalidad de los kazajos y a la inmigración principalmente rusa y eslava, aunque también han llegado alemanes del Volga y tártaros de Crimea, deportados por Stalin, y, posteriormente, kirguises, uzbecos, etc.

Hoy los kazajos representan sólo el $40 \%$ (30\% en 1950), mientras que los rusos equivalen a otro $40 \%(48 \%$ en 1950$)$ y los ucranianos al $5 \%$. 
Los eslavos residen en el Norte del país: en la región de colonización de «tierras virgenes» llevada a cabo por Jruschov a partir de 1954. Aqui fueron roturadas entre 1954 y 1964 unos 30 mill. de ha que suponen la producción del $15-20 \%$ de la cosecha anual de trigo de la actual CEI. Desde los años 70 se han cedido a la ganadería extensiva algunos millones de hectáreas y se ha conseguido elevar la productividad media hasta 10-15 $\mathrm{Qm} / \mathrm{ha}$ (umbral de rentabilidad=8 Qm/ha), llegando a obtener $18 \mathrm{mill}$. de $\mathrm{t}$ en 1993; algunos años, la climatología adversa puede provocar malas cosechas. El problema actual consiste en estabilizar a la población, intensificar la producción con el regadío y el uso de fertilizantes, e introducir cierta alternancia de cultivos, incorporando plantas forrajeras junto a los cereales.

La industria se ha desarrollado sobre todo en Karaganda, gran centro metalúrgico, donde se construyó el principal combinado de cobre de toda la antigua URSS. Otros centros industriales son Yekasgán, PavlodarEkibastur, Kustanai, etc. Aprovechando los grandes yacimientos de carbón de Karaganda (112 mill. de t en 1993, 8o productor mundial), de petróleo 23 mill. de t), de hierro (18 mill. de t), manganeso, cobre, cinc, níquel, minerales polimetálicos (plomo y oro), metales raros, como molibdeno y tugsteno, etc., se ha hecho del Norte de Kazajstán la región económica más importante de Asia Central. En 1993, la producción industrial ha descendido al $71 \%$ respecto a 1990 .

El Estado de Kazajstán constituye también una región estratégica para la CEl, con la gran base espacial de Baïkonur, al Oeste de Yerkasgán, y el centro de ensayos nucleares de Semipalatink, el principal de toda la exUnión Soviética.

Kazajstán presenta fuertes contrastes regionales. El Norte y el centro tienen unas bases económicas diversificadas y muy bien integradas con Rusia; están poblados por eslavos que lo han colonizado, realizando las dos transformaciones esenciales: la puesta en cultivo de las tierras vírgenes y la industrialización. La región del Caspio, al Oeste, es un frente pionero en zona árida, muy dependiente de la región rusa del Volga. La región meridional es la típica Asia Central, ya caracterizada anteriormente, poblada por kazajos y muy similar a sus vecinas del Sur, con regadios y producción de hortalizas, frutales, remolacha azucarera y algodón, y con algunos centros mineros aislados.

La transformación de Kazajstán fue presentada como un éxito de la economia soviética. Pero, hoy acusa importantes deficiencias: preponderancia de industrias pesadas (siderurgia, metalurgia, cemento y fertilizantes), gran consumidoras de un agua que escasea; densidades muy bajas de población, deficiente red de ferrocarriles y de carreteras, excesiva dependencia 
del mercado ruso. Esto es lo que explica la actitud de Razajstán ante la CEI y con relación a Rusia: es una firme partidaria de la reintegración de las repúblicas ex-soviéticas, cuanto más completa mejor, aunque quiera mantener las distancias con Rusia, declarando en 1993 el kazajo idioma oficial. Hoy impera el pragmatismo económico que se antepone al nacionalismo ( $60 \%$ de no kazajos).

Un nacionalismo radical kazajo podria traer como consecuencia la fragmentación territorial del Estado con la secesión del norte modernizado y fundamentalmente ruso. Un subsuelo rico en recursos energéticos $\left(7^{\underline{a}}\right.$ reserva mundial de carbón y de petróleo; también reservas importantes de gas natural) necesita la explotación por empresas extranjeras que aporten el capital; y para esto es imprescindible la estabilidad y la seguridad. Ello ha motivado que el Estado se haya opuesto a la privatización de la tierra y siga controlando los grandes combinados mineros, impidiendo una liberalización rápida. Quince centrales de importación-exportación controlan los intercambios de los productos considerados estratégicos.

c) Los otros cuatro Estados de Asia Central coinciden con el centro de la vasta depresión aralo-caspiana y su borde montañoso. El sello del islám está aquí mucho más vivo y las relaciones con China, India y el resto del mundo islámico han sido siempre muy estrechas.

Estos países musulmanes no son económicamente viables. Su función ha sido proveer de materias primas a las regiones industriales de la URSS, recibiendo de ellas los productos manufacturados; son dependientes en ambos sentidos.

Las estepas secas son recorridas por nómadas pastores; en los oasis del piedemonte, los sedentarios practican una agricultura tradicional de regadío. La política de desarrollo regional de la URSS montó aquí un dispositivo de control del agua en los rios Syr Daria y Amu Daria, poniendo en regadio 600.000 ha. Pero este "éxito" de la economía soviética no supo prever los desastres ecológicos posteriores, principalmente la desecación del mar de Aral que, desde entonces, ha reducido su extensión a la mitad, descendiendo en $14 \mathrm{~m}$ su nivel.

La industria apenas se ha desarrollado. Algunos centros mineros han determinado la aparición de centros metalúrgicos. Sólo Taskent y las otras capitales (Biskek, Dushambé y Ashjabad) se han convertido en centros de industrias ligeras: hilados de algodón, conservas vegetales, maquinaria agrícola, etc. El sistema de transporte une directamente a estos Estados con Rusia y ellos mismos están aislados, sin ninguna salida al mar. Con el $12 \%$ de la población éstos cuatro países aportan sólo el $6 \%$ del P.I.B. de la $\mathrm{CEI}$. Todos se han unido a la Comunidad de Estados Independientes desde 
el primer momento y ninguno ha roto los lazos con Rusia; pero la región se abre a nuevas influencias, con Pakistán, China y, sobre todo, Irán.

El de mayor peso económico es el Estado de Uzbekistan, poblado por 21 mill. de habs. Su agricultura se caracteriza por el monocultivo del algodón $(60 \%$ del total de la $\mathrm{CEI})$, con cuatro millones de hectáreas regadas, el algodón proporciona el $80 \%$ del valor de las exportaciones. Sin embargo, Uzbekistán sufre una dependencia alimentaria muy alta, a pesar de dedicar algunas tierras al arroz. El subsuelo es rico, con una producción de 45.000 mill. de $\mathrm{m}^{3}$ de gas en 1993 (6\% de la producción total de la CEI), y la explotación de petróleo y carbón, cuya producción puede aumentar por haberse descubierto recientemente nuevos yacimientos. La industria es muy escasa (algodón, cuero y seda) y desde 1990 se halla en fuerte retroceso (en 1993,64\% de la producción de 1990). La privatización de los medios de producción ha avanzado poco (sólo el 13\% de la empresas); el resto ha pasado de la gestión estatal a otra colectiva de los trabajadores, pero dentro de una economía planificada.

Turkmenistan es la cuarta república ex-soviética por su extensión, pero la última por su población (4 mill. de habs.; $72 \%$ de población turca); el $20 \%$ del territorio está ocupado por el desierto de Karakorum. Sólo el 2,5\% del territorio son tierras cultivadas, especializadas en algodón (16\% del total de la CEI). Junto con el algodón, su gran riqueza es el gas natural, con 84 mill. de $\mathrm{m}^{3}$ en 1993 (5 productor mundial), de los que exporta el 80 $\%$, y el petróleo, con 4,5 mill, de t. El subsuelo tiene reservas de oro, platino, bromo, yodo y azufre. La escasa industria está montada sobre las refinerías (12 mill. de t); tiene también industria textil (algodón y lino), fertilizantes y productos para instalaciones eléctricas. Turkmenistán ha sido el único de los Estados surgidos de la Unión Soviética que en 1993 tuvo un aumento del P.I.B. (3\%). Su relativa autonomía económica le hace ser la menos integradora de todas estas repúblicas ex-soviéticas, buscando las inversiones de los países occidentales.

Kirguistán aparece como una de las más pobres y en ella la ganadería adquiere una importancia especial. Los 4,5 mill. de habitantes se reparten entre el $50 \%$ de kirguises (nómadas), $18 \%$ de uzbekos y $18 \%$ de rusos; éstos han empezado a emigrar y, entre 1990 y 1992 se marcharon unos 100.000, quedando todavía en Kirguistán unos 700.000. El país es muy montañoso; más del $90 \%$ del territorio está a más de $1.000 \mathrm{~m}$ de altitud, 10 que le confiere un gran aislamiento y le proporciona recursos hidroeléctricos importantes. La agricultura es la primera actividad del pais, con un millón de hectáreas en regadio ( $72 \%$ de las tierras cultivadas), donde se obtienen cereales para el autoconsumo y algodón para la exportación. Es 
también gran productor de opio, aunque su cultivo está prohibido. El subsuelo se halla desprovisto de recursos, pero exporta energía hidroeléctrica y ha desarrollado una industria basada en la metalurgia no ferrosa, en las construcciones mecánicas y eléctricas y en la industria textil.

Kirguistán es la única república ex-soviética de Asia Central que se ha lanzado decididamente por la economía de mercado, pero sufre grandes penurias y ha experimentado un fuerte descenso de la renta per cápita: 1.200 dólares en 1992 y 700 en 1993. Intenta y conseguir ayudas del Banco Mundial, de EEUU y de Japón, mientras abre su economía fuera de la CEl: sus intercambios con otros países alcanzaron el $25 \%$ del comercio exterior en 1992 y el $40 \%$ en 1993.

Tayikistán, el más meridional de estos Estados, es también el más pobre, el de mayor influencia islámica y el más conflictivo. Con un Norte productor de algodón y un Sur ganadero, con algún centro metalúrgico aislado, como las instalaciones de enriquecimiento de uranio, donde se procesaba el $50 \%$ del uranio de la ex-URSS. Los 5,6 mill, de habitantes se hallan divididos entre el $58 \%$ de tayikos y el $23 \%$ de uzbekos; el $11 \%$ de rusos y ucranianos que residían en 1990 ya en 1993 han emigrado casi todos. El $80 \%$ es de religión musulmana, pero la lengua tayika está emparentada con el iraní, a diferencia del uzbeko que está emparentado con el turco (mapa de la Fig. 8).

En los últimos años ha sufrido un fuerte retroceso del P.I.B. (más del $50 \%$ desde 1990) y de la renta por cápita 600 dólares por habitante en 1993). La agricultura se basa en la ganaderia de ovinos y bovinos y en el regadio, donde se produce algodón; la privatización apenas ha progresado: en 1993 todavía el $80 \%$ era una agricultura socialista. La minería casi no existe; sin embargo, parece ser que el subsuelo encierra grandes reservas de carbón de alta calidad. La producción hidroeléctrica proporciona la mitad de la energía consumida y ha generado una industria de aluminio en Regar (50.000 t anuales), con bauxita importada; toda la actividad industrial se halla todavía en 1994 gestionada por empresas estatales.

El fundamentalismo islámico ha generado un conflicto armado; sin embargo, no es fácil que triunfe, ya que las diferencias de clan y de tribu son todavía más fuertes que el factor religioso. Esta guerra civil mezcla el conflicto religioso con las rivalidades étnicas y el enfrentamiento de posiciones políticas, unas pro-rusas y otras anti-rusas.

El hundimiento del poder central soviético y la pérdida de credibilidad de los partidos comunistas locales han hecho resurgir la fuerza del islám. La preocupación suscitada se debe a que no ha surgido un nacionalismo encauzado por el Estado, como ha ocurrido en otras re- 
públicas. Estas unidades políticas no existian antes de los años 30 y las identidades nacionales no encuentran raíces históricas o culturales, como en los Estados bálticos, en Armenia o en Ucrania. En el campo sigue vigente la fragmentación étnica o tribal, aunque la población se identifica con la comunidad de creyentes. Son sociedades fragmentadas y difícil de recomponer.

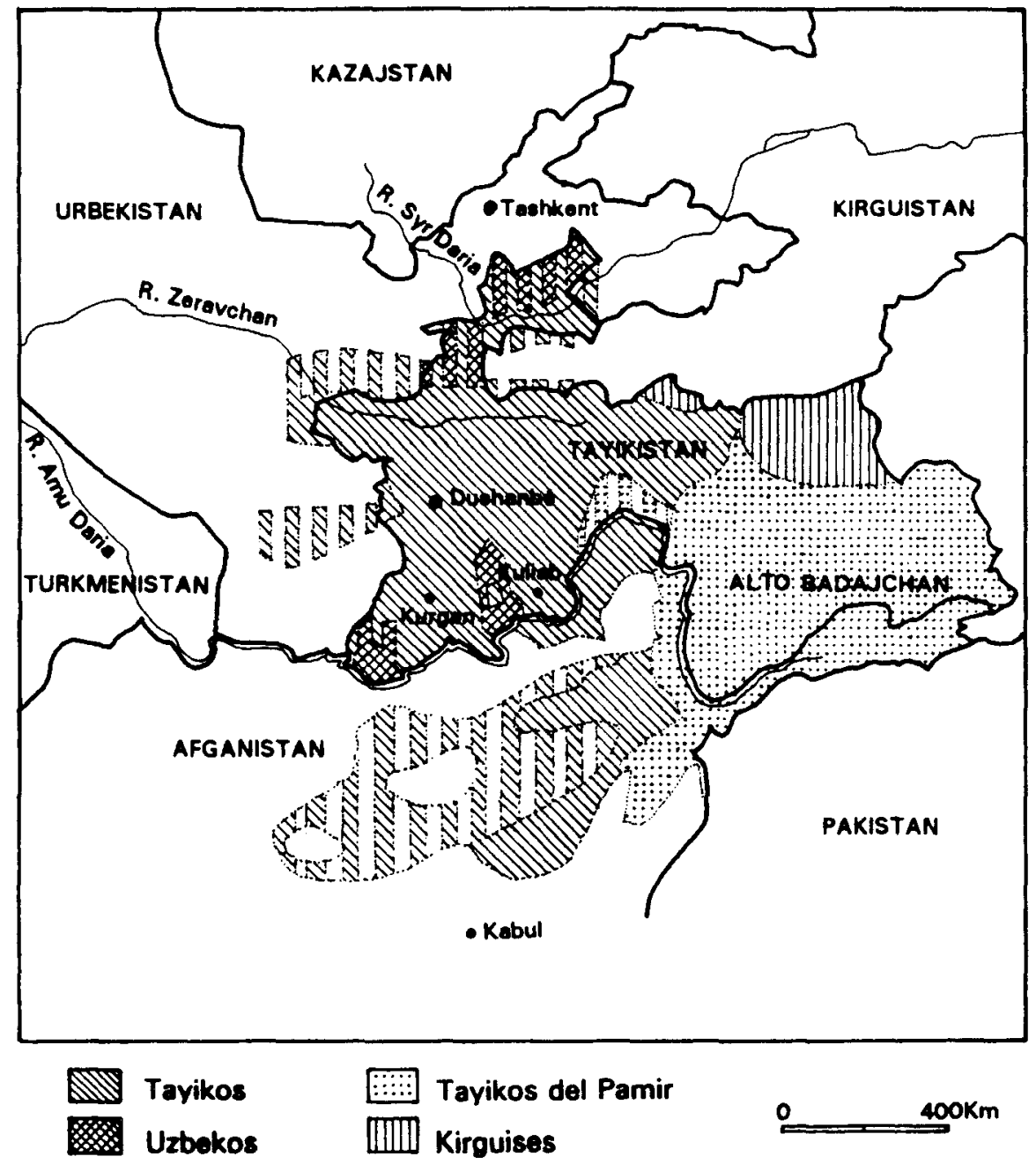

Figura 8. Grupos étnicos en Tayikistán. 
Por ello, son frecuentes los signos de xenofobia y surgen corrientes fundamentalistas, sobre todo en Uzbekistán y Tayikistán. Algunos intelectuales están proponiendo la constitución de un Gran Turkestán, en torno a Taskent, la gran metrópoli de Asia Central. Pero es poco probable que esta idea prospere, ya que las pequeñas repúblicas recelan de la hegemonía de Uzbekistán y los tayicos la rechazan. Ademas, ni a la CEI, ni a Rusia, ni a China les interesa esta solución.

\section{CONCLUSIÓN: LA DIFICIL ARTICULACIÓN DEL NUEVO ESPACIO EX-SOVIÉTICO}

Con el hundimiento del sistema socialista, el Estado multinacional soviético se fragmentó. Una nueva realidad política, formada por quince Estados independientes, ha sustituido a la gran potencia. Cada una de ellas ha impuesto su autonomía en un fragmento del espacio antes unitario, donde el imperio ruso, primero, y la Unión Soviética, después, fueron construyendo un sistema productivo con fuertes interrelaciones y muy interdependiente desde el punto de vista territorial.

Las ansias de independencia, especialmente intensas en algunos de estos Estados, contrasta con unas situaciones económicas desastrosas, provocadas por la ruptura y desorganización del sistema anterior; ademas, se han visto agravadas con las numerosas tensiones y conflictos interétnicos que se producen dentro de sus fronteras.

La imposibilidad real de romper todos los vínculos que unían a las repúblicas ex-soviéticas entre sí, especialmente, con Rusia, determinó la creación de la $\mathrm{CEI}$, una asociación peculiar de Estados con escasos compromisos comunes. La falta de acuerdos multilaterales en materia de comercio y de política económica está impidiendo el avance en la reestructuración del nuevo espacio político, caracterizado por fuertes contrastes económicos, sociales y regionales.

De todas maneras, parece claro que cualquier unión entre estas Estados soberanos, que antes o después terminará siendo inevitable, deberá construirse en torno a Rusia que, por su poderío económico y militar, es una indiscutible potencia mundial; a pesar de las dificultades que atraviesa en esta fase de transición poscomunista.

De cara al futuro, dos grandes retos esperan a los nuevos Estados: la culminación del proceso hacia una economía de mercado y una nueva vertebración de las repúblicas ex-soviéticas para aumentar la eficacia del sistema económico y dotar de coherencia a un espacio, hoy demasiado fragmentado. 


\section{BIBLIOGRAFÍA}

AtLASECO, 1995. Editions E.O.C., Paris, 1995.

BATER, J. H.(1989): The Soviet Scene. A Geographical Perspective. Edwar Arnold, London, $304 \mathrm{p}$.

Berton-Hogge, R. et Crosnier, M.A. (Dir.) (1993): Ex-URSS: Les Etats du divorce. Les études de la Documentation Française, Paris, 198 p.

Brand, D. (1981): L'Union Sovietique. Sirey, Paris, 178, p.

Calendario Atlante de Agostini, 1994, Instituto Geográfico de Agostini, Novara, 1993.

Crosnier, M. a A. (1993): "L'EX-URSS: le débuts de la transition économique", en BertonHOGge, R. y CROSNIER, M. A. (Dir.), pp. 91-107.

Gautier, A. el Reynaud, A. (1989): Génese et économie de l'URSS. Bréal, Paris, 238 p.

KERBLAY, B. (1994): “La recomposition territoriale et structurelle de l'ex-URSS". L'Information Géographique, 58, pp. 185-198.

LAVIGNE, M. (1992): "Perspectivas sobre el futuro de la reforma económica en la antigua Unión Soviética". Cuadernos del Este, 7, 1992, pp. 91-110.

Mauret, M. CL. (1982): Territoir et stratégie soviétique, Económica, Paris, $196 \mathrm{p}$.

MELvin Home, G. (1983): The Soviet Union. A geographical study. Longman, New York, 501 p.

NAGELS, J. (1993): La Tiers-mondisation de l'Ex-URSS. Ed. de l'Universite de Bruxelles, Bruxelles, $226 \mathrm{p}$.

Palazuelos, E. (1994): "Las repúblicas de la antigua Unión Soviética", en Europa del Este ¿transición o crisis? Instituto de Europa Oriental, Madrid, pp. 175-254.

Pal.azuelos, E.; GaRCimARTIN, C. y VARA, M." J. (1995): "La antigua Unión Soviética" en Europa del Este. El laberinto del cambio. Instituto de Europa Oriental, Madrid, pp. 161-282.

RaDVANY, J. (1990): L'URSS: régions et nations. Masson, Paris, 293 p.

SÁNCHEZ SÁNCHEZ, J. (1996): "La caída de la URSS y la difícil recomposición del espacio ex-soviético". Papeles de Geografía, no 23, Universidad de Murcia.

SchreIber, TH. et BARR, F. (Dir.) (1988): L'URSS et l'Europe de l'Est. La Documentation Française, Paris, $278 \mathrm{p}$. 